\title{
Essential Roles for ARID1B in Dendritic Arborization and Spine Morphology of Developing Pyramidal Neurons
}

\author{
Minhan Ka, ${ }^{1}$ Divyan A. Chopra, ${ }^{2}$ Shashank M. Dravid, ${ }^{2}$ and Woo-Yang Kim ${ }^{1}$ \\ ${ }^{1}$ Department of Developmental Neuroscience, Munroe-Meyer Institute, University of Nebraska Medical Center, Omaha, Nebraska 68198, and ${ }^{2}$ Department \\ of Pharmacology, Creighton University, Omaha, Nebraska 68178
}

\begin{abstract}
De novo truncating mutations in $A R I D 1 B$, a chromatin-remodeling gene, cause Coffin-Siris syndrome, a developmental disorder characterized by intellectual disability and speech impairment; however, how the genetic elimination leads to cognitive dysfunction remains unknown. Thus, we investigated the neural functions of ARID1B during brain development. Here, we show that ARID1B regulates dendritic differentiation in the developing mouse brain. We knocked down ARID1B expression in mouse pyramidal neurons using in utero gene delivery methodologies. ARID1B knockdown suppressed dendritic arborization of cortical and hippocampal pyramidal neurons in mice. The abnormal development of dendrites accompanied a decrease in dendritic outgrowth into layer I. Furthermore, knockdown of ARID1B resulted in aberrant dendritic spines and synaptic transmission. Finally, ARID1B deficiency led to altered expression of c-Fos and Arc, and overexpression of these factors rescued abnormal differentiation induced by ARID1B knockdown. Our results demonstrate a novel role for ARID1B in neuronal differentiation and provide new insights into the origin of cognitive dysfunction associated with developmental intellectual disability.
\end{abstract}

Key words: ARID1B; chromatin remodeling complex; dendrite arborization; intellectual disability; spine

Significance Statement

Haploinsufficiency of ARID1B, a component of chromatin remodeling complex, causes intellectual disability. However, the role of ARID1B in brain development is unknown. Here, we demonstrate that ARID1B is required for neuronal differentiation in the developing brain, such as in dendritic arborization and synapse formation. Our findings suggest that ARID1B plays a critical role in the establishment of cognitive circuitry by regulating dendritic complexity. Thus, ARID1B deficiency may cause intellectual disability via abnormal brain wiring induced by the defective differentiation of cortical neurons.

\section{Introduction}

Intellectual disability is the most common developmental disorder, and is characterized by significant limitations in cognitive functioning and adaptive behaviors (Daily et al., 2000; Ellison et al., 2013). The prevalence of intellectual disability is estimated to affect $1-3 \%$ of the general population (Maulik et al., 2011; Ellison et al., 2013). The common syndromes associated with intellectual disability include autism, Down syndrome, fragile $\mathrm{X}$ syndrome,

Received June 16, 2015; revised Jan. 12, 2016; accepted Jan. 22, 2016.

Author contributions: M.K. and W.-Y.K. designed research; M.K., D.A.C., S.M.D., and W.-Y.K. performed research; M.K., D.A.C., S.M.D., and W.-Y.K. analyzed data; W.-Y.K. wrote the paper.

Research reported in this publication was supported by an award from the National Institute of Neurological Disorders and Stroke of the National Institutes of Health under award R01-NS-091220 and an Institutional Development Award from the National Institute of General Medical Sciences of the National Institutes of Health under award number P20-GM-103471 to W.Y.K. We thank Drs. Robert Norgren and Anna Dunaevsky for valuable advice and comments on the manuscript.

The authors declare no competing financial interests.

Correspondence should be addressed to Woo-Yang Kim, Department of Developmental Neuroscience, MunroeMeyer Institute, University of Nebraska Medical Center, Omaha, NE 68198. E-mail: wooyang.kim@unmc.edu.

DOI:10.1523/JNEUROSCI.2321-15.2016

Copyright $\odot 2016$ the authors $\quad 0270-6474 / 16 / 362723-20 \$ 15.00 / 0$
Coffin-Siris syndrome, and fetal alcohol spectrum disorder. Although intellectual disability can be caused by environmental insults, such as infection, trauma, and teratogens during pregnancy or at birth, the vast majority of cases are caused by genetic abnormalities (Ropers, 2010; Ellison et al., 2013). Recent progression of genetic studies including whole-genome sequencing, exome sequencing, and genome-wide rearrangement analyses has increased understanding of the etiology by identifying associated genes.

ARID1B encodes AT-rich interactive domain containing protein $1 \mathrm{~B}$, also known as BAF250B, and is a member of the mammalian SWitch/Sucrose Non-Fermentable (SWI/SNF) chromatin remodeling complex (Ho and Crabtree, 2010; Ronan et al., 2013). Using a DNA-binding domain, this protein targets the SWI/SNF complex to specific genes and facilitates DNA access for transcription factors (Wang et al., 2004; Li et al., 2010). Importantly, recent genetic studies have revealed that mutations in the ARID1B gene cause nonsyndromic and syndromic intellectual disability including Coffin-Siris syndrome (Halgren et al., 2012; Hoyer et al., 2012; Santen et al., 2012; Tsurusaki et al., 2012). 
Mutations observed include deletions and truncations due to de novo nonsense or frameshift mutations as well as translocation, leading to ARID1B haploinsufficiency in the individuals with intellectual disability (Halgren et al., 2012; Hoyer et al., 2012; Santen et al., 2012). Additionally, mutations of the ARID1B gene are also associated with autism and childhood neuroblastoma, which often accompany intellectual disability (Halgren et al., 2012; Sausen et al., 2013; De Rubeis et al., 2014; Iossifov et al., 2014). Mouse embryonic stem cells lacking ARID1B show a reduced proliferation rate and perturbation of differentiation (Yan et al., 2008). Neurobiological functions of ARID1B during brain development are unknown. Understanding how this genetic abnormality leads to alterations in brain development and cognitive function is essential for developing effective therapeutic interventions.

Dendritic and synaptic differentiation is important for establishing functional cognitive circuitry during brain development. Thus, abnormalities in these developmental processes are critically associated with the pathology of intellectual disability (Huttenlocher, 1974; Machado-Salas, 1984; Belichenko et al., 1994; Kaufmann and Moser, 2000; Armstrong, 2005). We hypothesized that ARID1B plays important roles in dendritic arborization and spine formation during mammalian brain development. To investigate the functions and mechanisms of ARID1B in neuronal development, we used an in utero gene delivery strategy to eliminate ARID1B gene in developing neurons. In this study, we report that $A R I D 1 B$ is required for dendritic arborization and synaptic development in the brain. ARID1B knockdown resulted in aberrant dendritic branching, spine formation, and synaptic transmission. Furthermore, ARID1B elimination changed the expression of neurite growth-associated genes. Together, our findings reveal a novel function of ARID1B in pyramidal neuron development in the brain, and thereby advance our understanding of the mechanisms underlying intellectual disability.

\section{Materials and Methods}

Materials. Tetrodotoxin (Alomone Labs), picrotoxin (Tocris Bioscience), D-AP5 (Tocris Bioscience), and NBQX (Abcam) were purchased.

Plasmids. We generated two short hairpin (sh) ARID1Bs using two different targeting sequences ( $5^{\prime}$-GGAACCAGTTATGACCGAAGGC-3' and 5'-GCAAGTCAAAGGACAGCTATG-3') and their complement sequences. The oligomers were cloned into a modified pSuper-Basic vector or pLVX-shRNA2 vector (Clontech), as previously described (Kim et al., 2006). Additionally, we generated sh microARID1B (shmiARID1B) by cloning the same targeting sequences into pcDNA6.2-GW/EmGFP-miR (Life Technologies). For control, nonsilencing shRNAs were generated using scrambled targeting sequences (5'-GACGACTGCGACGGGATAATA-3'; 5' -GA ATACGACCGACACCTACTA- $\left.3^{\prime}\right)$. Arc and c-Fos coding sequences were prepared by long-range PCR using cDNA from the mouse brain as a template. Amplified fragments were then digested with EcoRI and XbaI (Clontech) and were ligated into the overexpression vector pcDNA3.1 (Clontech). An ARID1B mutant construct that is resistant to shARID1B was generated by point mutating $6 \mathrm{nt}$ in wobble positions at $\sim 3978 \mathrm{bp}$. The shARID1Bresistant mutant was prepared by long-range fusion PCR using cDNA from the mouse brain as a template and ligated into the overexpression vector pcDNA3.1 (Clontech). Finally, the sequences of the targeting vector were confirmed by nucleotide sequencing. Human ARID1B plasmid was purchased from Addgene.

Immunostaining. Immunostaining of brain sections or dissociated cells was performed as described previously (Kim et al., 2005; Ka et al., 2014a). The following primary antibodies were used: mouse antiARID1B (Abcam), mouse anti-microtubule-associated protein 2 (MAP2; Covance), rabbit anti-T-box brain 1 (Tbr1; Millipore Bioscience Research Reagents), rabbit anti-Cut-Like Homeobox 1 (Cux1; Santa Cruz Biotechnology), rabbit anti-glial fibrillary acidic protein (GFAP;
DAKO), guinea pig anti-vGlut (Millipore), and rabbit anti-vesicular GABA transporter (vGAT; PhosphoSolutions). Appropriate secondary antibodies conjugated with Alexa Fluor dyes (Invitrogen) were used to detect primary antibodies.

In utero electroporation. In utero electroporation was performed as described previously (Ka et al., 2014a,b). Timed pregnant female mice from embryonic day 14.5 (E14.5) of gestation were deeply anesthetized, and the uterine horns were gently exposed. The lateral ventricles of an embryonic brain were injected with plasmid DNA $(2 \mu \mathrm{g} / \mu \mathrm{l})$ and $0.001 \%$ fast green using a Picospritzer II (Parker Inc.). Electroporation was achieved by placing two sterile forceps-type electrodes on opposing sides of the uterine sac around the embryonic head and applying a series of short electrical pulses using a BTX ECM 830 electroporator (five pulses with $100 \mathrm{~ms}$ length separated by $900 \mathrm{~ms}$ intervals were applied at $45 \mathrm{~V}$ ). The small electrical pulses drive charged DNA constructs into surrounding cells in the embryonic brain. Embryos were allowed to develop in utero for the indicated time. For hippocampal gene delivery, one lateral ventricle of an E14.5 brain was injected with a DNA mixture. The electrodes were placed at an angle to the opposite way of cortical targeting.

Morphometry. For the quantification of lengths, numbers, or thicknesses of dendrites and leading processes, images of 20 different brain sections at periodic distances along the rostrocaudal axis were taken with Zeiss LSM510 and LSM710 confocal microscopes and a Nikon Eclipse epifluorescence microscope with a QImaging CCD camera attached. Ten mice were used for each experiment (control mice, $n=5$; mutant mice, $n=5$ ). Dendritic morphologies in cultured neurons were also assessed with the microscopes. More than 20 fields scanned horizontally and vertically were examined in each condition. Cell numbers are described in the figure legends. The images were analyzed using ZEN (Zeiss), LSM image browser (Zeiss), QCapture software (QImaging), and ImageJ. The calculated values were averaged, and some results were recalculated as relative changes versus control.

For assessing colocalization, the ImarisColoc software of the Imaris software package (version 6.5, Bitplane) was used. A 3D perspective was rendered by the Surpass module of the software. The number of synapses was assessed by immunostaining samples with antibodies to excitatory (vGlut1) and inhibitory (vGAT) synaptic markers, and by counting vGlut1 (or vGAT) and GFP colocalized puncta on dendrites transfected with shRNAs. After background subtraction, the threshold value for each channel was automatically adjusted, following an algorithm previously described (Costes et al., 2004). The colocalized voxels representing synapses were reported as the number of vGlut1 (or vGAT) and GFPpositive puncta per $30 \mu \mathrm{m}$. Pearson's colocalization coefficient was chosen in the ImarisColoc software. This coefficient allows checking the statistical validity of the colocalization selection. For qualitative analysis of colocalization between ARID1B and Tbr1 (or ARID1B and Cux1) was performed within the immunostained volume of the brain. The colocalized voxels representing ARID1B on Tbr1 fluorescence were reported as the percentage of colocalized intensity.

For the Sholl analysis, concentric circles with an increasing radius (10 $\mu \mathrm{m}$ increments) were placed around the cell body. The number of intersections of the dendrites and the concentric circles per radial distance from the soma were quantified. Briefly, 8-bit images of cultured neurons were traced using the NeuronJ plugin for ImageJ, and tracing files ( ${ }^{*}$.ndf files) were generated. The data were organized and converted to SWC files using MATLAB (Mathworks), and the connectivity of the tracings was checked in NeuronStudio.

Primary neuron cultures and transfection. Primary neuronal culture was described previously (Kim et al., 2006, 2009a). Briefly, cerebral cortices or hippocampi from E13.5-E18.5 mice were isolated and dissociated with trituration after trypsin/EDTA treatment. Then, the cells were plated onto poly-D-lysine/laminin-coated coverslips, and cultured in the medium containing neurobasal medium, 5\% serum, B27 supplement, and $\mathrm{N} 2$ supplement.

Mouse cortical or hippocampal neurons were transfected with various plasmids as described previously (Ka et al., 2014a,b). Briefly, embryonic cortices or hippocampi were dissociated and suspended in $100 \mu \mathrm{l}$ of Amaxa electroporation buffer with 1-10 $\mu \mathrm{g}$ of plasmid DNA. Then, suspended cells were transferred to an Amaxa electroporation cuvette 
and electroporated with an Amaxa Nucleofector apparatus. After electroporation, cells were plated onto coated coverslips, and the medium was changed $4 \mathrm{~h}$ later to remove the remnant transfection buffer.

Lentivirus preparation. The same oligomers that were used for generating shARID1B were subcloned into BamHI and EcoRI sites of pLVXshRNA2 vector (Clontech) according to the manufacturer protocol. For efficient packaging to decrease the risk of recombination and produce replication competent viruses, $\mathrm{pMDLg} / \mathrm{pRRE}$ and $\mathrm{pRSV}-\mathrm{Rev}$ were used (Dull et al., 1998). Viral particles were pseudotyped with pMD2.G plasmid encoding vesicular stomatitis virus G-protein. The lentivirus was generated by cotransfection of HEK 293T cells with four plasmids using a liposome-mediated gene transfer. After $48 \mathrm{~h}$, the supernatant was collected and filtered through $0.45 \mu \mathrm{m}$ cellulose acetate filters. Higher titer stocks were obtained by an ultrafiltration device (Millipore) and stored frozen at $-80^{\circ} \mathrm{C}$. Lentiviral titers were determined by infecting HEK 293 T cells at a density of $5 \times 10^{5}$ cells/well with a serial dilution of the stock virus in the presence of polybrene $(8 \mu \mathrm{g} / \mathrm{ml})$. The culture medium was changed $4 \mathrm{~h}$ later, and the cells were incubated for $2 \mathrm{~d}$. High titers of engineered lentiviruses were produced $\left(1 \times 10^{8}\right.$ infectious $\left.\mathrm{U} / \mathrm{ml}\right)$, as measured by green fluorescence colony formation on HEK 293T cells.

Western blotting. Western blotting was performed as described previously (Kim et al., 2004, 2009b). Cellular lysates from cultured neurons were prepared using RIPA buffer, and the protein content was determined by a Bio-Rad Protein Assay system. For examining nuclear/cytoplasmic localization, cultured neurons were fractionated into nuclear and cytoplasmic lysates using NE-PER Nuclear and Cytoplasmic Extraction Reagents (Thermo Scientific). Proteins were separated on a 3-8\% or $4-12 \%$ SDS-PAGE gradient gel and transferred onto a nitrocellulose membrane. Then the membrane was incubated with rabbit anti-c-Fos (Santa Cruz Biotechnology), rabbit anti-Arc (Santa Cruz Biotechnology), mouse anti-ARID1B (Abcam), rabbit anti-p-CREB (Cell Signaling Technology), mouse anti-ERK1/2 (Cell Signaling Technology), rabbit anti-phospho-ERK1/2 (Cell Signaling Technology), rabbit anti-p38 (Cell Signaling Technology), rabbit anti-phospho-p38 (Cell Signaling Technology), rabbit anti-JNK (Cell Signaling Technology), or rabbit anti-phospho-JNK (Cell Signaling Technology) at $4^{\circ} \mathrm{C}$ overnight. Appropriate secondary antibodies conjugated to HRP were used (Cell Signaling Technology), and ECL reagents (GE Healthcare) were used for immunodetection.

For quantification of band intensity, blots from three independent experiments for each molecule of interest were used. Signals were measured using ImageJ software and were represented by relative intensity versus control. GAPDH was used as an internal control to normalize band intensity.

$R T-P C R$. RNA was extracted from cultured neurons using TRIzol reagent (Invitrogen), and cDNA was synthesized from $1 \mu \mathrm{g}$ of total RNA using oligo-dT and random hexamers using the Thermo Scientific Verso cDNA synthesis kit (ThermoFisher Scientific). A measure of $1 \mu \mathrm{l}$ of cDNA was used in a RT-PCR using Master Mix (Promega). The sequences of the primers used were as follows: c-Fos, forward 5' -TTGCCAATCTGCTGAAAGAG-3', and reverse 5'-ACGTTGCTGATGCTCTTGAC-3' (240 bp); Arc, forward 5'-CTGAGCCACCTGGAAGAGTAC-3', and reverse 5'-CTGGTCAA GTGGCTCACCCTG-3' (240 bp); Stathmin-Like 2 (STMN2), forward, 5' AACAGCAATGGCCTACAA- $3^{\prime}$, and reverse $5^{\prime}$-TCTTCTCTGCCAATT GTT-3' (319 bp); G-protein-regulated inducer of neurite outgrowth (GPRIN1), forward 5'-CCGACCCACAGCCTTCTT-3', and reverse 5' GCTTCCCAGACGTGGTGG-3' (319 bp); growth-associated protein 43 (GAP43), forward 5'-AAGTCCTGCTCTGAATTA-3', and reverse 5'GGGGCTTCATCCTTCTTA-3' (319 bp); ARID1B, forward 5' -ATG GCGCTTTTATCGAACCT-3', and reverse 5' -CCGGCACATCATG TCTACAC-3' (198 bp); and GAPDH, forward 5'-AAGGTCATCCCAG AGCTGAA- $3^{\prime}$, and reverse 5' -AGGAGACAACCTGGTCCTCA-3' (196 bp).

Chromatin immunoprecipitation assay. The chromatin immunoprecipitation (ChIP) assay was performed using the Magna-CHIP A Chromatin Immunoprecipitation Kit (Millipore) according to the manufacturer protocol. We cultured cortical cells from E14.5 mice for $4 \mathrm{~d}$ and infected them with a lentivirus to knock down ARID1B. Formaldehyde at $1 \%$ concentration was added to the culture medium at room temperature to cross-link chromatin proteins to genomic DNA. After $10 \mathrm{~min}$, the cells were washed twice and scraped off in ice-cold PBS containing Protease Inhibitor Cocktail II (Millipore). Cells were pelleted, resuspended in lysis buffer, and subjected to sonication to reduce the size of DNA to $\sim 200-1000$ bp in length. Protein A magnetic beads and $5 \mu \mathrm{g}$ of anti-IgG, anti-Brgl (Abcam), or anti-AcetylHistone $\mathrm{H} 3$ antibody (Abcam) were added to the chromatin solution and incubated overnight at $4^{\circ} \mathrm{C}$ with rotation. After washing and elution, crosslinks of the protein/DNA complexes were reversed to free DNA by the addition of proteinase $\mathrm{K}$ and incubation at $62^{\circ} \mathrm{C}$ for $2 \mathrm{~h}$ followed by further incubation at $95^{\circ} \mathrm{C}$ for $10 \mathrm{~min}$. Then, the DNA fragments were purified and used for PCR. The primer sequences were c-Fos forward 5'-TGTATGCC AAGACGGGGGTT- $3^{\prime}$ and reverse $5^{\prime}$-AGAGCAGAGCTGGGTGG GAG-3' or Arc forward 5'-TGTGAAGGGGCGGGTCCTTGA-3' and reverse 5'-AAGGGAGCAGAGCCGGCGGCT-3'. All primers were initially tested for their specificity by running PCR samples on an agarose gel.

Whole-cell electrophysiology and data analysis. Voltage-clamp wholecell recordings were obtained from cultured neurons at room temperature $\left(22-25^{\circ} \mathrm{C}\right)$. An external solution containing $150 \mathrm{~mm} \mathrm{NaCl}, 3 \mathrm{~mm}$ $\mathrm{KCl}, 10 \mathrm{~mm}$ HEPES, $6 \mathrm{~mm}$ mannitol, $1.5 \mathrm{~mm} \mathrm{MgCl}_{2}$, and $2.5 \mathrm{~mm} \mathrm{CaCl}_{2}$, $\mathrm{pH}$ 7.4, was used for the recordings. Glass pipettes with a resistance of 5-8 $\mathrm{m} \Omega$ were filled with an internal solution consisting of $110 \mathrm{~mm}$ cesium gluconate, $30 \mathrm{~mm} \mathrm{CsCl}, 5 \mathrm{~mm}$ HEPES, $4 \mathrm{~mm} \mathrm{NaCl}, 0.5 \mathrm{CaCl}_{2}, 2 \mathrm{~mm}$ $\mathrm{MgCl}_{2}, 5 \mathrm{~mm}$ BAPTA, $2 \mathrm{~mm} \mathrm{Na}$ ATP, and $0.3 \mathrm{~mm} \mathrm{Na}$ GTP, pH 7.35. Neurons were held at a holding potential of $-70 \mathrm{mV}$ for mEPSCs and 0 $\mathrm{mV}$ for mIPSCs. For recording mEPSCs, $1 \mu \mathrm{M}$ tetrodotoxin and $100 \mu \mathrm{M}$ picrotoxin were added to the external recording solution, and for mIPSCs $1 \mu \mathrm{m}$ tetrodotoxin, $10 \mu \mathrm{M}$ NBQX, and $50 \mu \mathrm{M}$ D-AP5 were added. The signal was filtered at $2 \mathrm{kHz}$ and digitized at $20 \mathrm{kHz}$ using an Axon Digidata 1440A analog-to-digital board (Molecular Devices). Recordings were performed from three independent cultures. Recordings with a pipette access resistance of $<20 \mathrm{~m} \Omega$ and with $<20 \%$ changes during the duration of recording were included. The mEPSC and mIPSC recordings were analyzed using Mini Analysis software (Synaposoft) with an amplitude threshold set at $6-8 \mathrm{pA}$. The frequency, amplitude, and decay were measured in each group.

Statistical analysis. Normal distribution was tested using the Kolmogorov-Smirnov test, and variance was compared. Unless otherwise stated, statistical significance was determined by two-tailed unpaired Student's $t$ test for two-population comparison or one-way ANOVA with Bonferroni correction test for multiple comparisons. Data were analyzed using GraphPad Prism and were presented as the mean \pm SEM. For determining and confirming the $N$ numbers (sample sizes), we have performed a power analysis using the Java applets program developed by Dr. Russel Lenth (University of Iowa, Iowa City, IA; http:// homepage.stat.uiowa.edu/ $\sim$ rlenth/Power $/)$. The values for the power $(1-\beta)$ and the type I error rate $(\alpha)$ were 0.8 and 0.05 (or 0.01 ), respectively. Each experiment in this study was performed blind and randomized. Animals were assigned randomly to the various experimental groups, and data were collected and processed randomly. The allocation, treatment, and handling of animals were the same across study groups. Control animals were selected from the same litter of the test group. Pups weighing $<20 \%$ of the intergroup and intragroup average were excluded from the experiments. The individuals conducting the experiments were blinded to group allocation and the allocation sequence.

\section{Results}

\section{Neural expression of ARID1B}

To begin exploring the role of ARID1B in neuronal development, we first assessed the expression patterns of ARID1B by immunostaining in the developing cortex. At E15 and E20 of embryonic developmental stages, ARID1B was highly expressed in the cortical plate (Fig. $1 A$ ). In contrast, low levels of ARID1B expression were detected in the ventricular/subventricular zone and intermediate zone at these stages. ARID1B-positive cells were found throughout the cerebral cortex at postnatal day 7 (P7) and P21, as cortical layers expand. Still, white matter in the intermediate zone was barely stained with an ARID1B antibody. The patterns of ARID1B immunolabeling in the cortical plate suggested that the protein is expressed in cortical neurons. Thus, we colabeled P7 
A
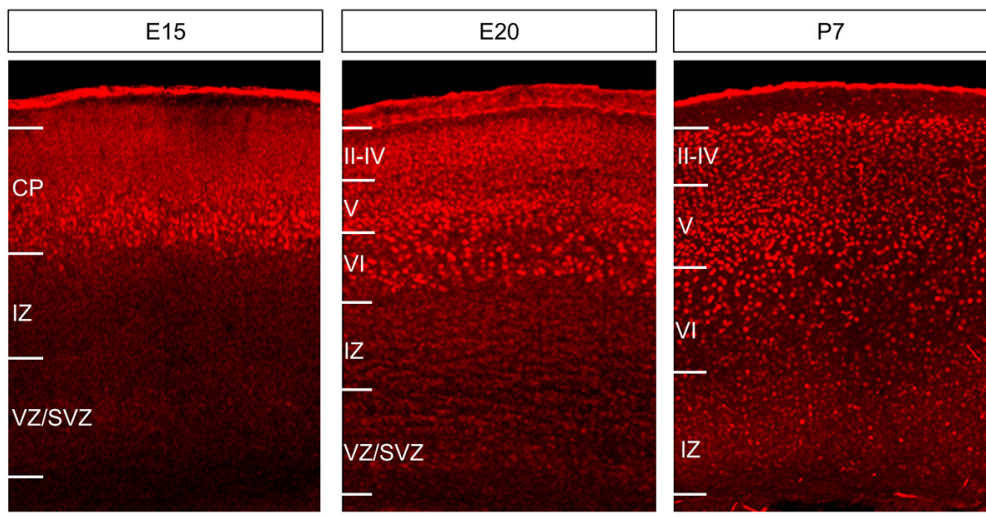

B
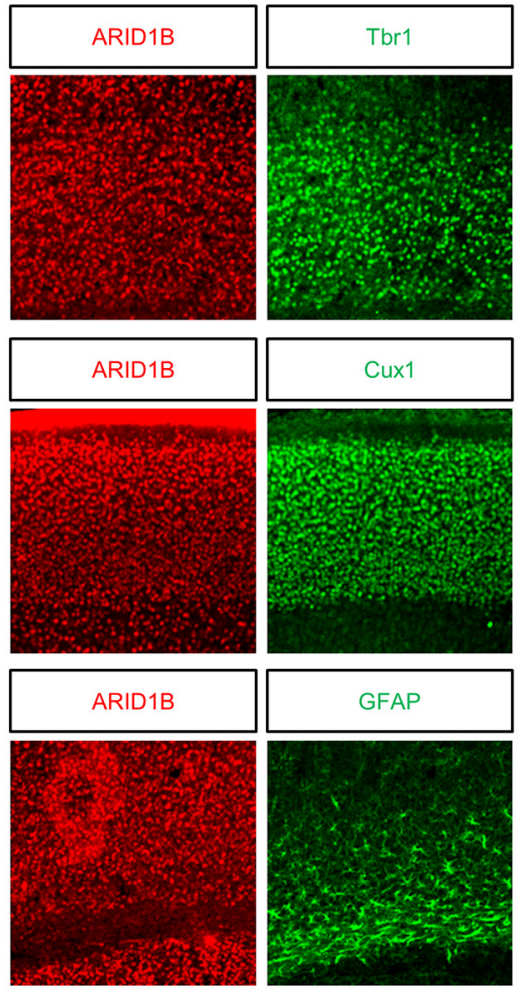

C
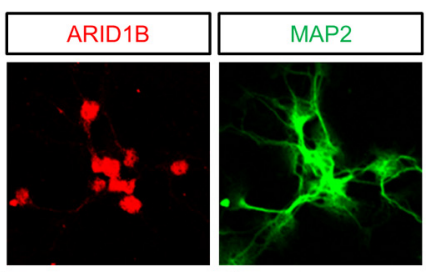

ARID1B MAP2
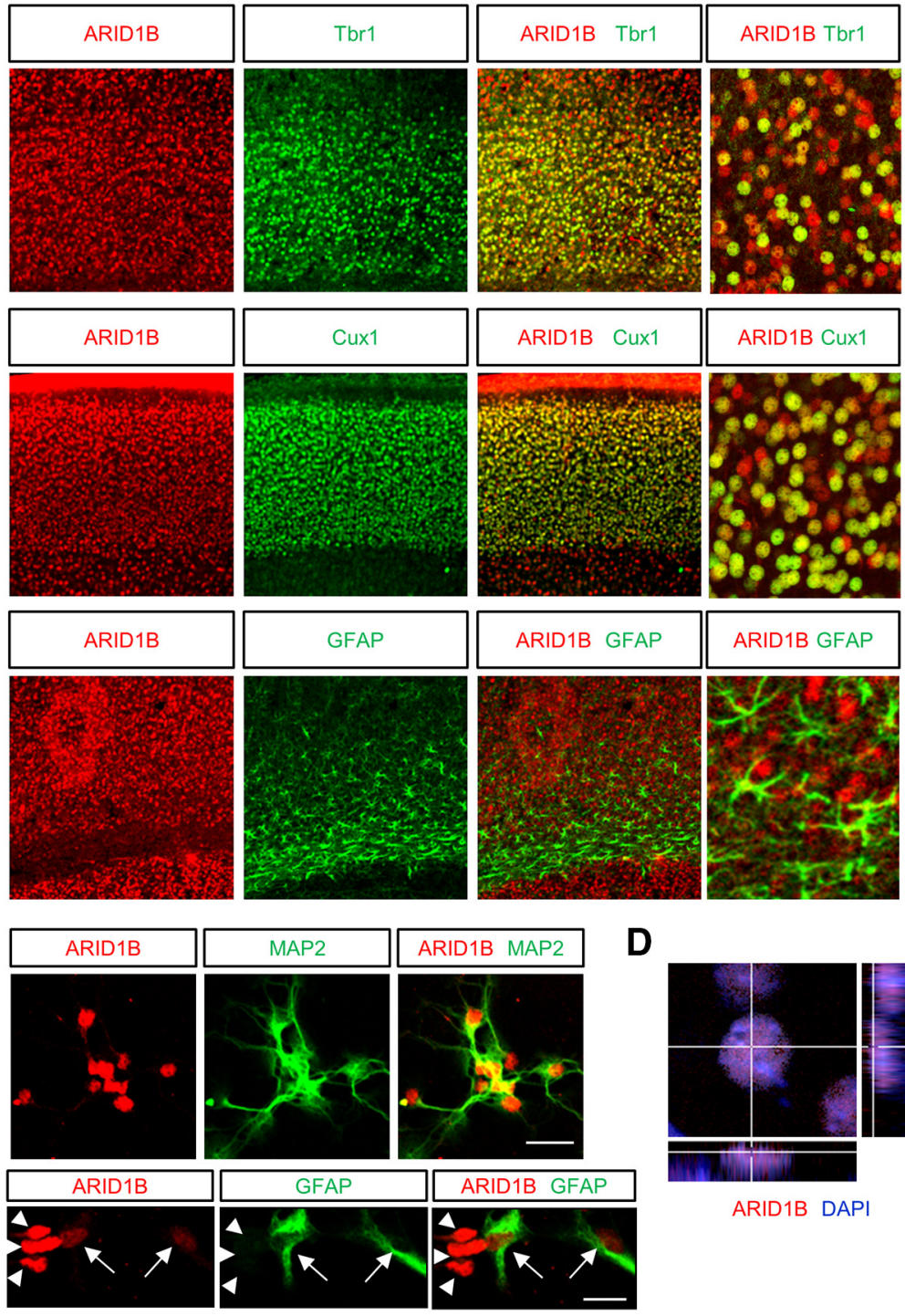

D

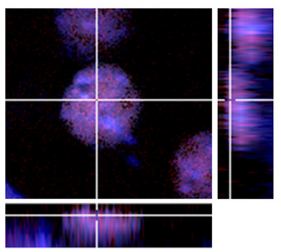

ARID1B DAPI
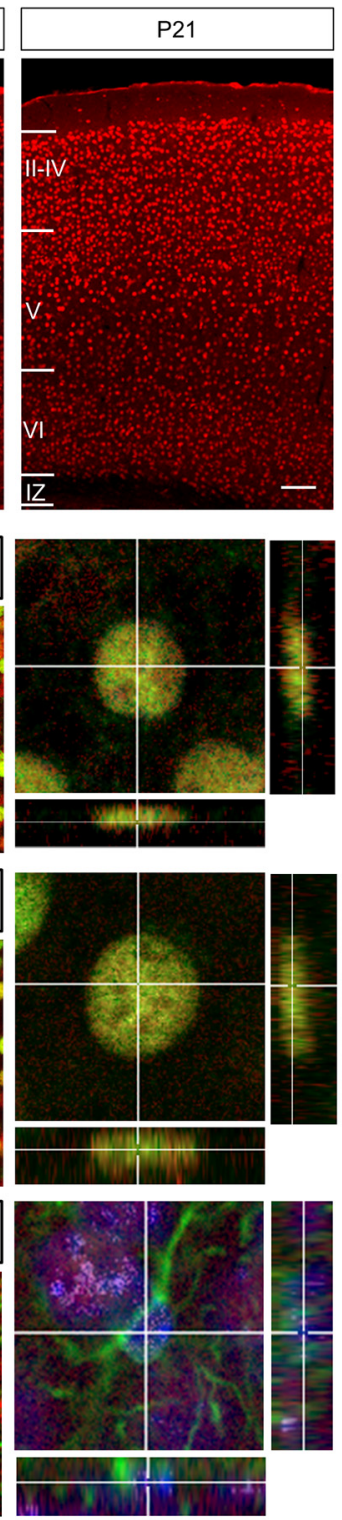

$\mathbf{E}$

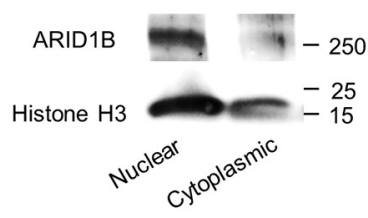

Figure 1. Expression patterns of ARID1B in the developing cortex. A, Left and left middle, Expression of ARID1B in embryonic mouse brains. Immunostaining for ARID1B showed that the protein was highly expressed in the cortical plate of the developing mouse brain where neurons are present. Right middle and right, ARID1B expression in postnatal mouse brains. ARID1B-positive cells were found broadly throughout the cortical layers. Scale bar, $150 \mu \mathrm{m}$. CP, Cortical plate; IZ, intermediate zone, VZ, ventricular zone, SVZ, subventricular zone; II-VI, cortical layers II-VI. B, ARID1B was expressed in pyramidal neurons of lower and upper cortical layers marked by Tbr1 and Cux 1 at $\mathrm{P7}$ (top and middle rows), suggesting roles for ARID1B in pyramidal neuron differentiation. However, ARID1B was barely expressed in GFAP-positive astrocytes (bottom row). Right panels showed orthogonal views of z-stacked confocal images to confirm the coexpression of ARID1B and Tbr1 (or Cux1) in the cell. The fourth column shows higher-magnification images. C, Top panels, ARID1B immunostaining in MAP2-positive neurons in culture. Scale bar, $25 \mu \mathrm{m}$. Bottom panels, Low level of ARID1B was detected in GFAP-positive astrocytes (arrows), compared with GFAP-negative cells (arrowheads). Scale bar, $20 \mu \mathrm{m}$. D, ARID1B was present in the nucleus as it was colocalized with DAPI. $\boldsymbol{E}$, Intracellular localization of ARID1B. P7 brain lysates were fractionated into the nuclear and the cytosolic fractions. Western blotting showed that ARID1B protein was enriched in the nuclear fraction. Histone H3 was blotted as a control. $\boldsymbol{F}$, Top panels, ARID1B was strongly expressed in the granule cell layer of the hippocampus at P7. Middle row, Higher-magnification images of the granule layer of the hippocampus after coimmunostaining of ARID1B with NeuN, ARID1B, and calbindin, or GFAP antibody. Bottom panels show that ARID1B expression was markedly reduced in GFAP-positive cells (arrow) compared with negative cells (arrowhead). Scale bar, $500 \mu \mathrm{m}$. G, Quantification of ARID1B levels in different types of cells by ImageJ. (Figure legend continues.) 
$\mathbf{F}$
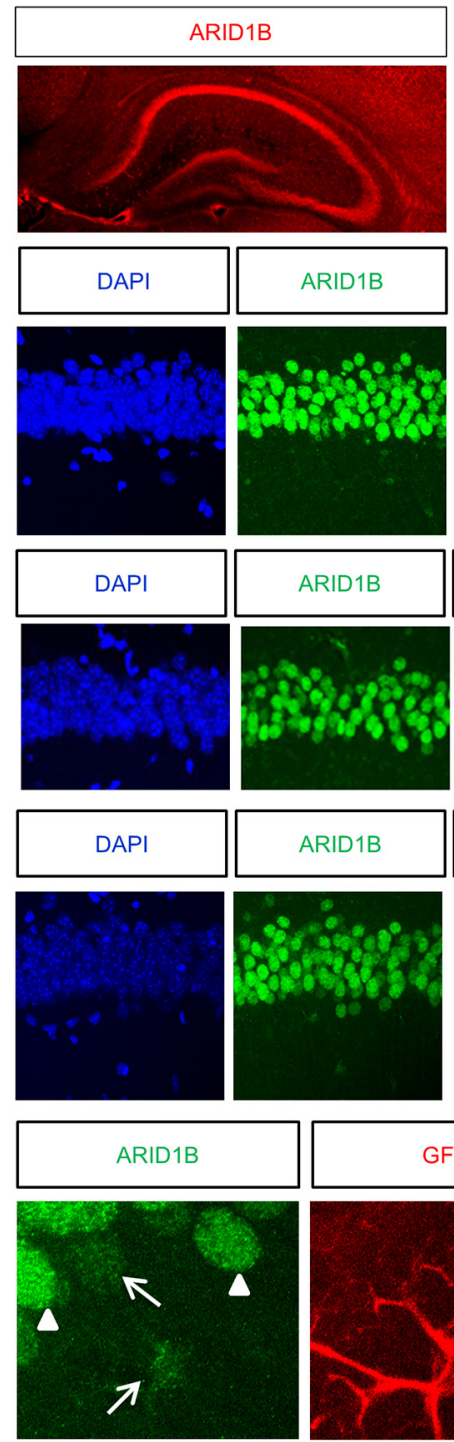
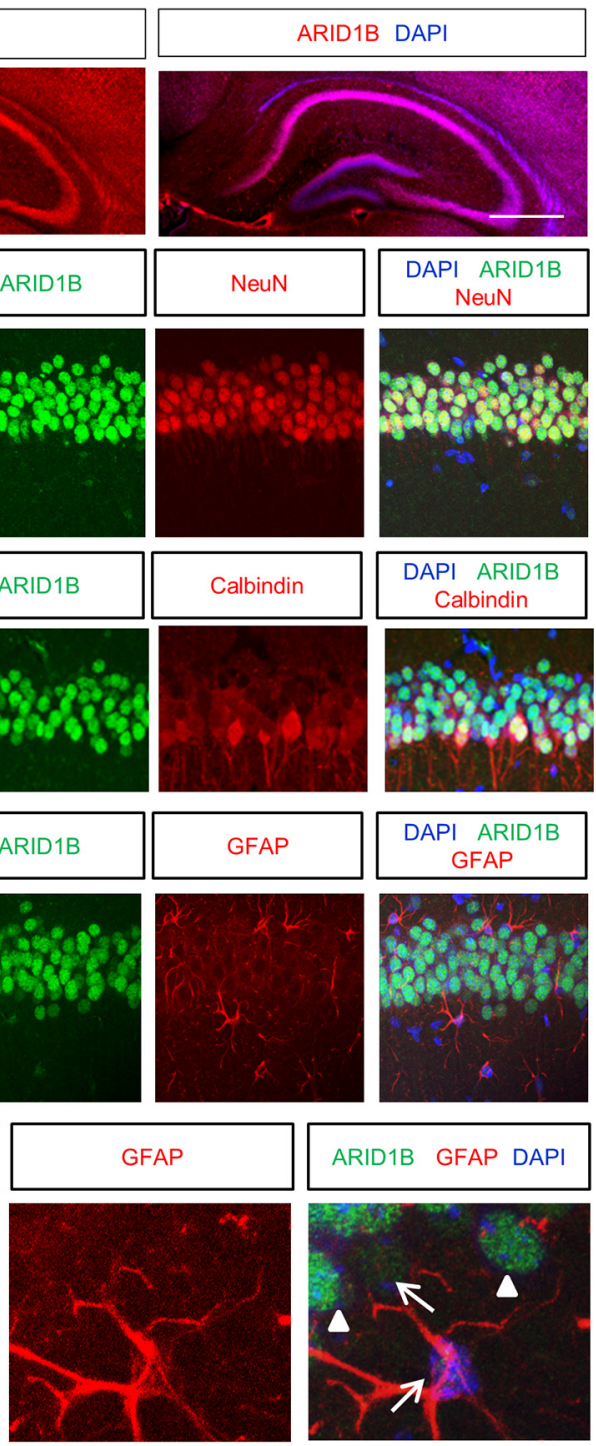
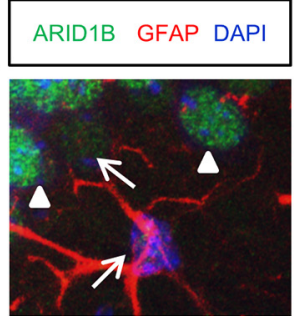
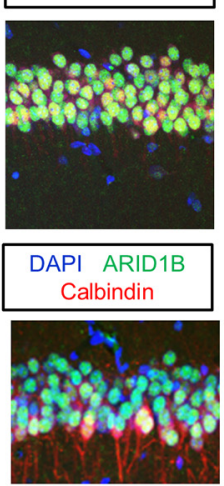

G

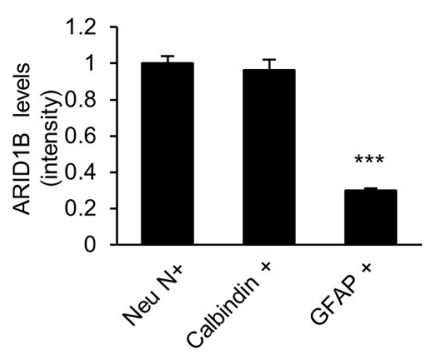

H

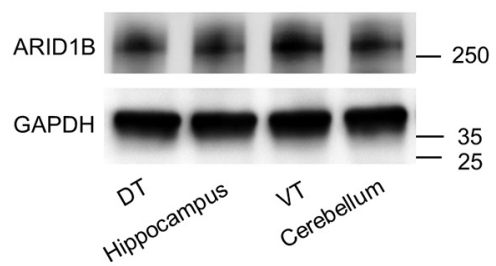

I

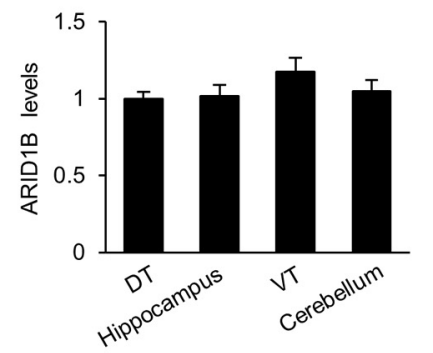

$\mathbf{J}$

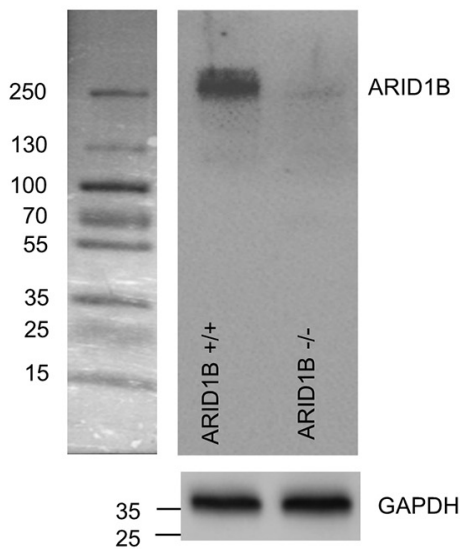

Figure 1. (Figure legend continued.) Twenty sections from five mice for each condition were analyzed. Statistical significance was determined by two-tailed Student's $t$ test. ${ }^{* * *} p<0.001$. $\boldsymbol{H}$, Western blotting showing ARID1B expression in several brain regions. DT, dorsal telencephalon; VT, ventral telencephalon. $\boldsymbol{I}$, Quantification of $\boldsymbol{H}$. $n=3$ independent experiments using three mice. Statistical significance was determined by two-tailed Student's $t$ test. No significance was found. J, Western blotting with an ARID1B antibody was performed using lysates from wild-type and ARID1B knock-out stem cells.

brain sections with antibodies against ARID1B and neuronal layer markers, and found that ARID1B was highly expressed in cortical pyramidal neurons marked by Cuxl or Tbr 1 (Fig. $1 B$, top and middle panels). Furthermore, colabeling of ARID1B with a MAP2 antibody in cortical culture confirmed the expression of the protein in neurons (Fig. $1 \mathrm{C}$, top panels). In contrast to the strong expression in neurons, ARID1B was barely detected in astrocytes in the developing brain (Fig. $1 B$, bottom panels). To confirm the exclusive expression of ARID1B in neurons, we assessed ARID1B levels in cultured cells dissociated from the developing cerebral cortex. While MAP2-positive neurons showed robust expression of ARID1B, GFAP-positive astrocytes expressed ARID1B at a markedly lower level compared with the neighboring cells (Fig. 1C, bottom panels). Thus, ARID1B is expressed almost exclusively in neuronal populations in the developing brain. Within the cell, ARID1B was localized in the nucleus, as shown by the colabeling of ARID1B and DAPI (Fig. 1D), reflecting its identity as a member of a chromatin remodeling complex. To confirm the intracellular localization of ARID1B, we performed Western blotting to detect ARID1B in fractionated cellular compartments such as the nucleus and the cytoplasm. A Western blot showed that ARID1B was mostly localized in the nucleus, as expected, which is similar to a chromatin-associated protein, histone H3 (Fig. 1E). Finally, there was strong expression of ARID1B in the pyramidal neuron layer of the hippocampus at P7 (Fig. 1F). NeuN-positive general neu- 
rons and calbindin-positive interneurons expressed ARID1B, while astrocytes showed little expression in the hippocampus. The level of ARID1B was similar between NeuN-positive and calbindin-positive cells, but it was decreased significantly in GFAP-positive cells (Fig. 1G). These results show that ARID1B is expressed in cortical and hippocampal neurons during embryonic and postnatal brain development, and suggest the role of the protein in neuronal development. Additionally, we examined ARID1B expression levels in several areas of E20 mouse brains, including the dorsal telencephalon, the hippocampus, the ventral telencephalon, and the cerebellum (Fig. 1H). ARID1B was expressed broadly throughout the brain regions. The expression level appeared to be higher in the ventral telencephalon than in other areas, but the difference was not significant (Fig. 1I). The ARID1B antibody was validated by Western blotting using lysates from ARID1B knock-out stem cells (Fig. 1J).

\section{ARID1B knockdown suppresses dendritic arborization}

To investigate the role of ARID1B in pyramidal neuron morphogenesis, we generated two shRNAs (shARID1Bs) that recognize ARID1B transcripts. The validity of shARID1Bs was tested by Western blotting and immunostaining. A Western blot showed that shARID1B-mediated knockdown of ARID1B decreased the level of ARID1B by 52\% compared with control conditions [shARID1B, $0.48 \pm 0.03$ arbitrary unit (A.U.) ratio to control band intensity (A.U.); control: $1.0 \pm 0.01$ A.U.; $p<0.0001$; Fig. $2 A, B]$. Then, we introduced either a control or shARID1B construct by in utero electoporation into E14.5 embryos and assessed the dendritic morphology at P7. The electroporation resulted in the labeling of soma and dendrites of layer II-IV pyramidal neurons in the developing cortex. Control neurons start generating apical and basal dendritic branches (Fig. 2C,D).

Generally, control neurons developed several primary apical and basal dendrites, and elaborated multiple short branches from the primary apical dendrites. However, ARID1B knockdown resulted in smooth apical dendrites without dendritic branches. The number of primary dendrites was decreased by $50 \%$ in ARID1B-deficient neurons (shARID1B: $2.6 \pm 0.3$; control: $5.2 \pm$ $0.4 ; p=0.000399$ ) compared with controls (Fig. $2 E$ ). Furthermore, ARID1B deficiency dramatically suppressed the formation of secondary and tertiary apical dendrites by $68 \%$ (number of dendrites in shARID1B: $1.16 \pm 0.2$; number of dendrites in control: $3.61 \pm 0.3 ; p<0.0001$ ) and $89 \%$ (number of dendrites in shARID1B: $0.3 \pm 0.2$; number of dendrites in control: $2.8 \pm 0.4$; $p<0.0001)$, respectively, which are indicative of dendritic arborization. Dendritic morphology of pyramidal neurons becomes rapidly complicated with time during early postnatal brain development.

We next wondered whether the dendritic branching impairment in ARID1B-deficient neurons is transient or persists into later postnatal stages. Thus, we assessed dendritic arborization patterns in P14 brain samples. While control neurons further elaborated secondary and tertiary apical dendrites, as well as primary basal dendrites, ARID1B-deficient neurons showed a markedly simple dendrite morphology (Fig. $2 F, G)$. Compared with control neurons, the numbers of primary, secondary, and tertiary dendrites were strongly reduced by $30 \%$ in ARID1B-deficient pyramidal neurons (shARID1B: $4.3 \pm 0.4$; control: $6.1 \pm 0.4 ; p=0.031933$ ), $44 \%$ (shARID1B: $1.5 \pm 0.2$; control: $2.8 \pm 0.4 ; p=0.014004)$, and $88 \%$ (shARID1B: $0.4 \pm 0.3$; control: $3.2 \pm 0.4 ; p=0.000243$ ), respectively (Fig. $2 H$ ). ARID1B elimination also led to decreases in the lengths of total and apical dendrites by $58 \%$
(shARID1B: $204 \pm 15 \mu \mathrm{m}$; control: $485 \pm 28 \mu \mathrm{m} ; p=$ $0.000334)$ and $65 \%$ (shARID1B: $121 \pm 10 \mu \mathrm{m}$; control: $345 \pm$ $17 \mu \mathrm{m} ; p<0.0001)$. Additionally, we also assessed the effect of ARID1B in a neuronal culture that was treated with antimitotic agent cytosine arabinoside (AraC). Adding AraC reduces glial contamination by eliminating proliferating glial cells. GFAP and MAP2 double immunostaining confirmed that cells in the AraC-treated culture were mostly neurons (Fig. $2 J$ ). AraC-treated cultures contained 98.8\% MAP2-positive neurons and 1.2\% GFAP-positive glial cells, while control cultures had $89.2 \%$ neurons and $10.8 \%$ glial cells. ARID1B-deficient neurons generated shorter dendrites (shARID1B: $379 \pm 36$ $\mu \mathrm{m}$; control: $1100 \pm 54 \mu \mathrm{m} ; p=0.000396)$ and fewer dendrites (shARID1B: $7 \pm 0.7$; control: $14.4 \pm 0.9 ; p=0.000323$ ) in the culture compared with controls (Fig. $2 I, J$ ), indicating the ARID1B effect is cell autonomous. Dendritic complexity was also assessed by Sholl analysis, which measures the number of crossing points of dendrites in a distance from the soma. Similar to the results cited above, dendritic complexity, shown as the numbers of intersections and terminals of dendrites in concentric circles, was reduced in ARID1B-deficeint cells compared with controls (shARID1B: $4.8 \pm 0.7$; control: $10.1 \pm 0.9 ; p=0.000205$; Fig. $2 K$ ).

We tested two different shRNAs against ARID1B using different targeting sequences and observed that both shRNAs significantly decreased dendritic branching in the developing brain. Nevertheless, we further generated shmiRNAs against ARID1B due to the potential off-target effect of shRNAs. A precious study (Alvarez et al., 2006) has shown that RNA interference with shRNAs can have off-target effects that reduce the complexity of dendrites in the brain. shmiRNAs drive the production of long RNA hairpins with endogenous miRNA loop and flanking sequences, and thus undergo more natural miRNA processing and largely overcome the off-target effects of shRNA (Bauer et al., 2009; Baek et al., 2014). We found that ARID1B knockdown using shmiARID1B resulted in apical and basal dendrites with markedly shorter dendrites (shmiARID1B: $148 \pm 12 \mu \mathrm{m}$; control: $333 \pm 9 \mu \mathrm{m} ; p<$ 0.0001 ) and fewer dendritic branches (primary shmiARID1B: $4.4 \pm 0.2$; primary control: $6.2 \pm 0.4 ; p=0.003815$; secondary shmiARID1B: $2.1 \pm 0.4$; secondary control: $4.6 \pm 0.2 ; p=$ 0.000672 ; tertiary shmiARID1B: $0.3 \pm 0.02$; tertiary control: $4.6 \pm 0.4 ; p<0.0001$; Fig. $2 L-N)$, which were observed in shARID1B experiments (Fig. $2 C-K$ ). Furthermore, we generated an ARID1B mutant construct that is resistant to shARID1B by point mutating $6 \mathrm{nt}$ in wobble positions at 3978 bp. Then we electroporated E14 embryos with the construct and an shARID1B in utero, and assessed dendritic phenotypes at P14. We found that coexpression of the shARID1B-resistant mutant suppressed the inhibitory effect of shARID1B on dendritic development, as assessed in the length (control: $392 \pm 13 \mu \mathrm{m}$; shARID1B: $193 \pm 16 \mu \mathrm{m}$; shARID1B/shARID1B-resistant: $383 \pm 15 \mu \mathrm{m} ; p=0.000133$ between shARID1B and shARID1B/hARID1B-resistant) and the number of secondary apical dendrites (control: $5 \pm 0.3$; shARID1B: $2.4 \pm 0.2$; shARID1B/shARID1B-resistant: $5.2 \pm$ $0.4 ; p=0.000243$ between shARID1B and shARID1B/ shARID1B-resistant) and tertiary apical dendrites (control: $5.2 \pm 0.4$; shARID1B: $1.4 \pm 0.3$; shARID1B/shARID1B-resistant: $5 \pm 0.6 ; p=0.000323$ between shARID1B and shARID1B/shARID1B-resistant; Fig. 2O,P).

Orientation of dendritic branches contributes to the establishment of the local connectivity. We observed that control 
A

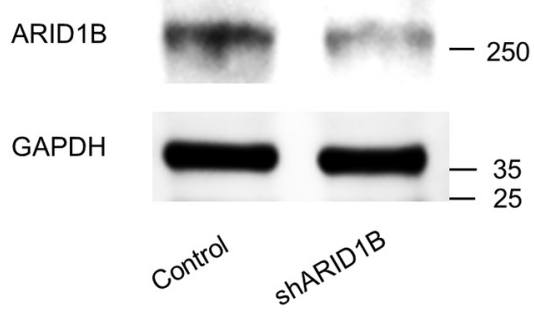

C
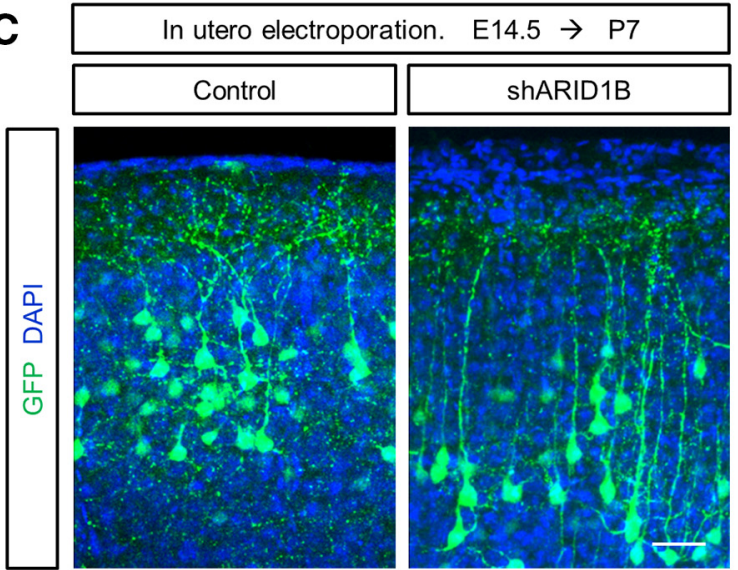

F
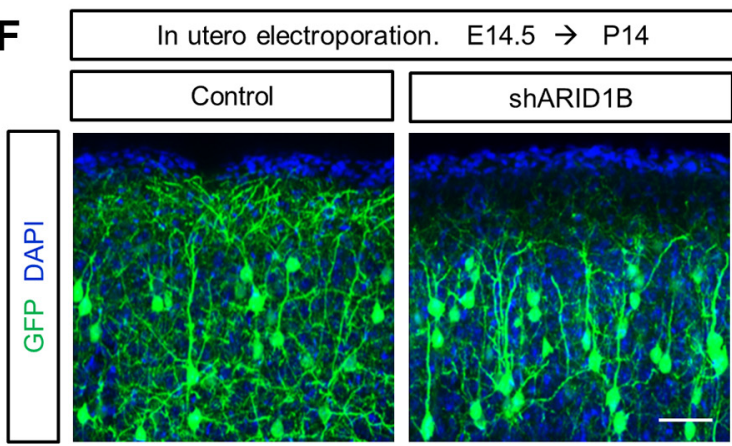

B

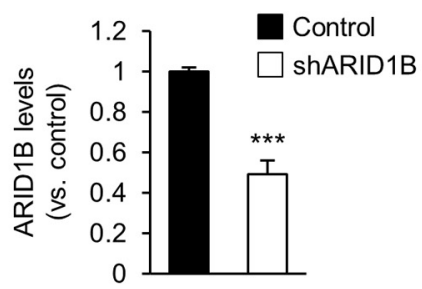

D
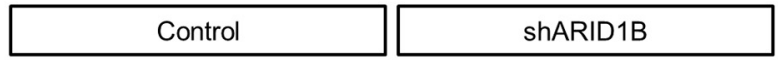

$\mathbf{E}$
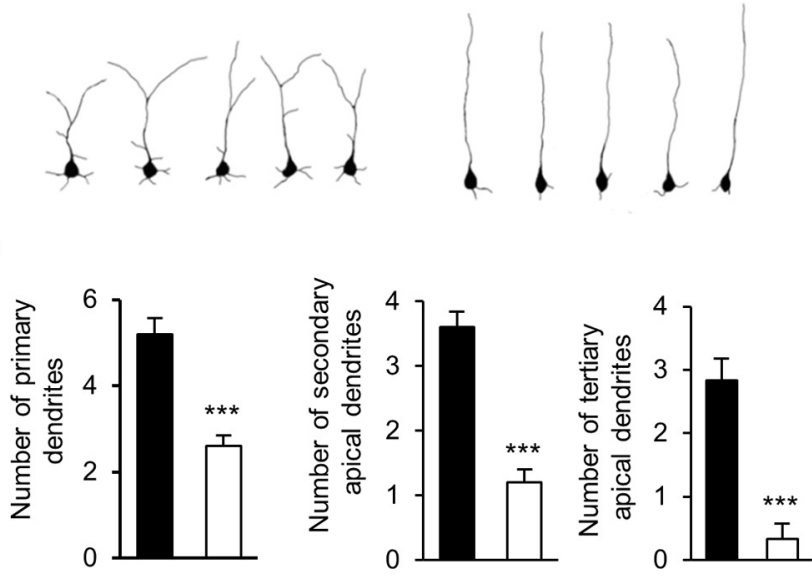

G
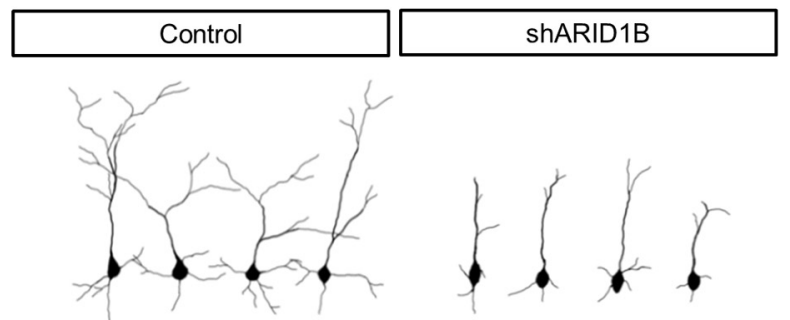

H
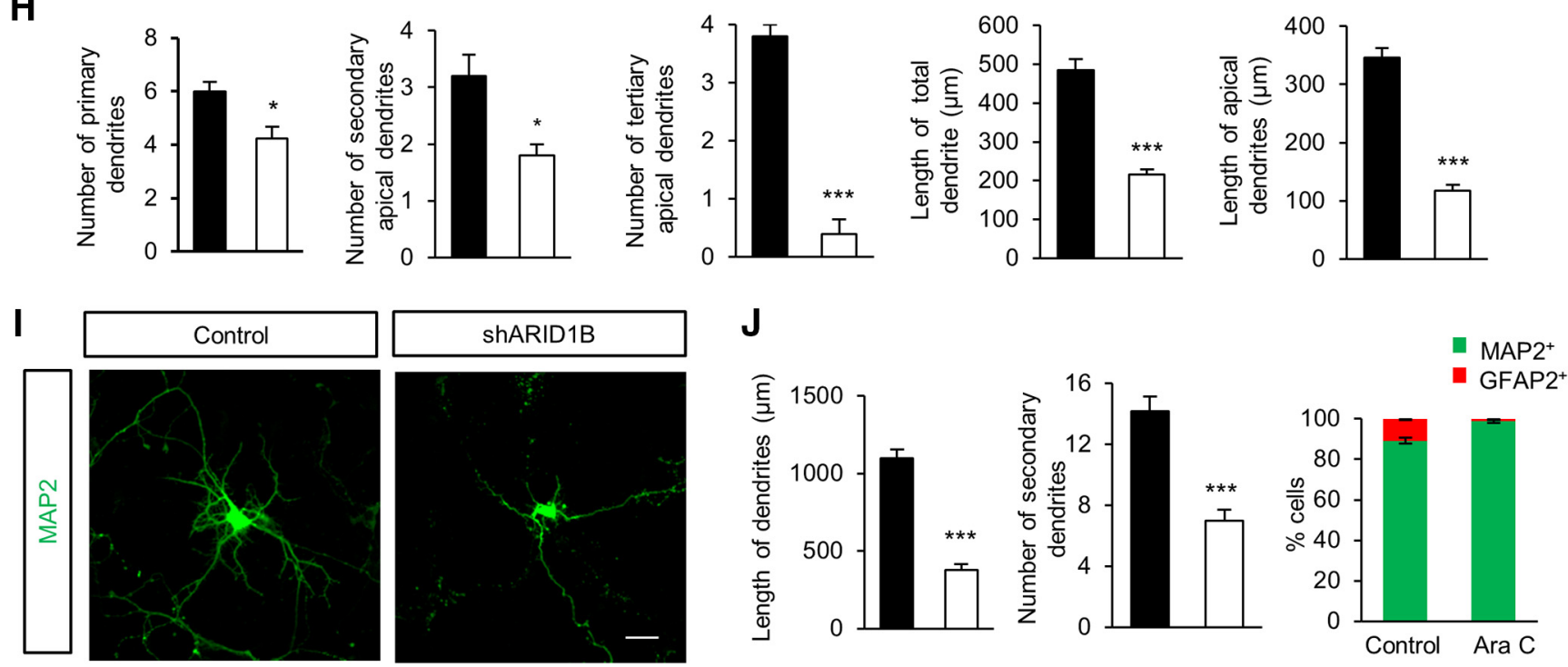

Figure 2. ARID1B regulates dendritic arborization of cortical pyramidal neurons. A, shARID1B knocks down endogenous ARID1B in cortical neurons. Isolated cortical cells from E16.5 mice were transfected with either a scrambled shRNA control or an shARID1B construct, and cultured for $7 \mathrm{~d}$. Western blots showed that the level of ARID1B was markedly decreased in cellular lysates of shARID1B transfection, compared with the level in control lysates. $\boldsymbol{B}$, Quantification of $\boldsymbol{A}$. The band intensities were measured using ImageJ. $n=3$ independent cortical cultures using three mice. Statistical significance was determined by two-tailed Student's $t$ test. ${ }^{* *} p<0.001$. C, Elimination of ARID1B suppresses dendritic arborization of pyramidal neurons in the developing cortex. E14.5 mouse brains were electroporated in utero with a nonsilencing control or shARID1B construct to target radially migrating pyramidal neurons. The electroporated (Figure legend continues.) 


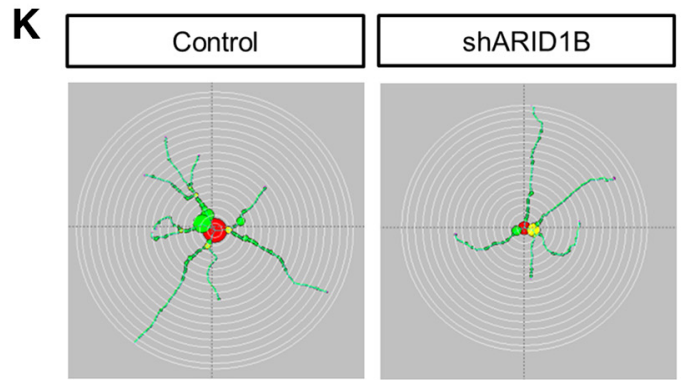

L
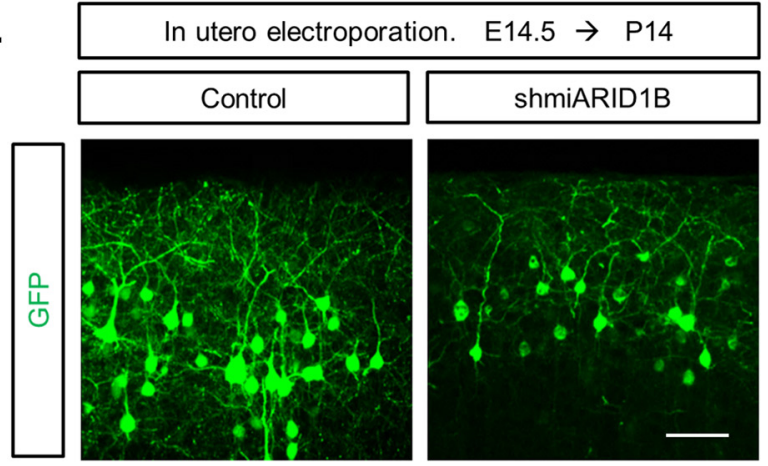

$\mathbf{N}$
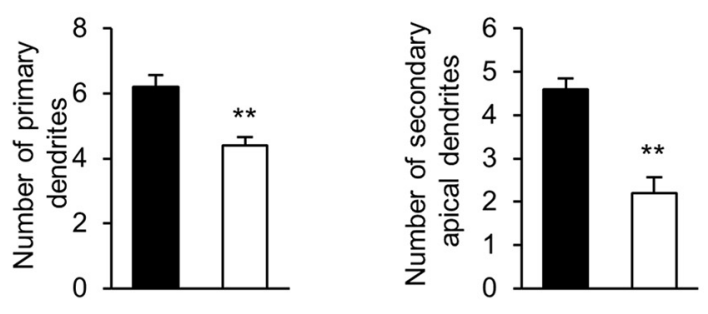
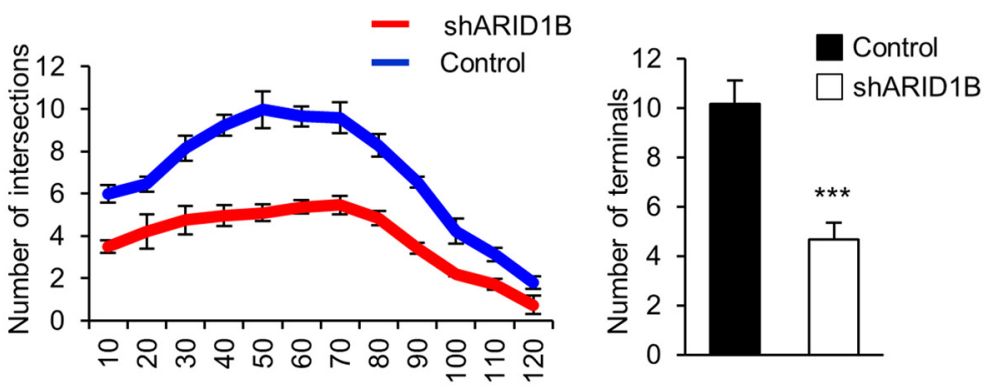

Distance from soma $(\mu \mathrm{m})$

\section{M}

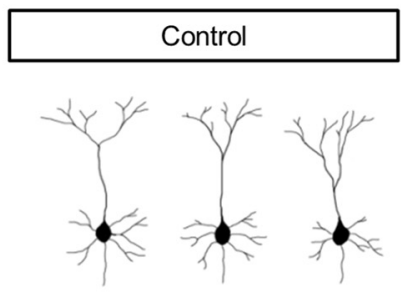

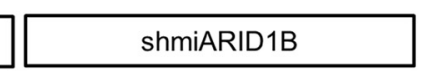

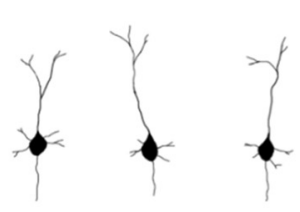

Control

$\square$ shmiARID1B
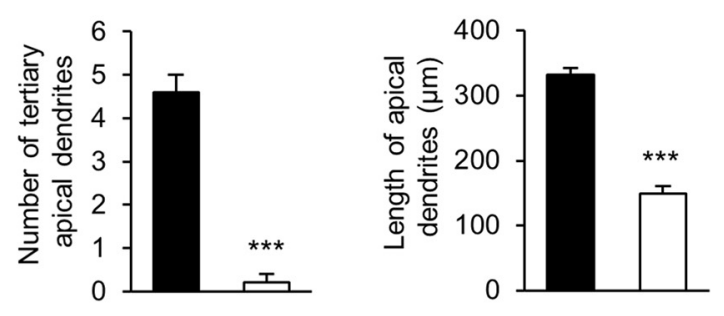

O

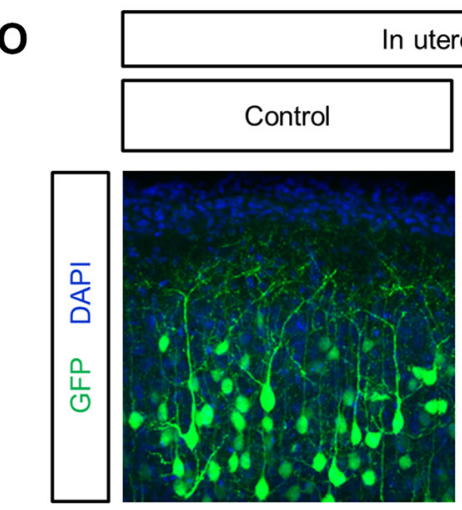

In utero electroporation. E14.5 $\rightarrow$ P10
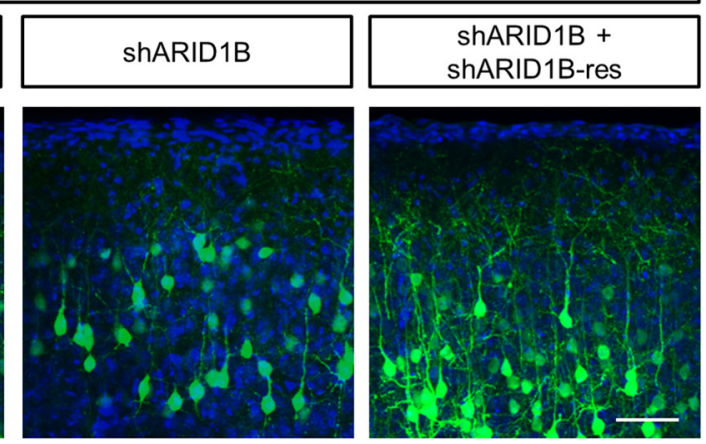

$\mathbf{P}$
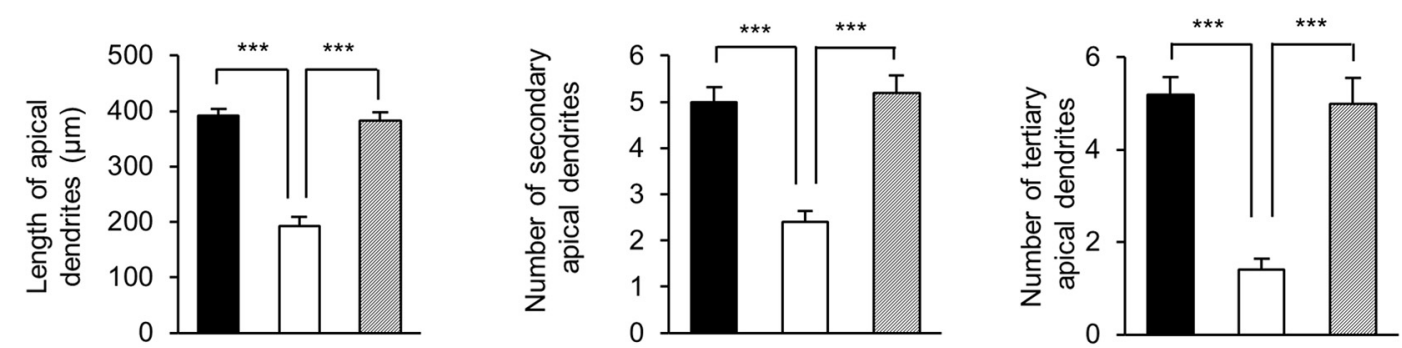

Figure 2. (Figurelegend continued.) brains were collected at P7, and dendritic morphologies were assessed by visualizing GFP expression. Scale bar, $20 \mu \mathrm{m}$. D, Representative single-cell traces of control and shARID1B-electroporated pyramidal neurons shown in C, demonstrating the reduced complexity in ARID1B-deficient pyramidal neurons. $E$, The numbers and lengths of dendrites were quantified. The number of primary, secondary, and tertiary dendrites were decreased in ARID1B-deficient neurons, compared with controls. $n=75$ cells from five mice for each condition. Statistical significance was determined by two-tailed Student's $t$ test. Data shown are the mean \pm SEM. Stars indicate a significant difference when compared with controls. (Figure legend continues.) 


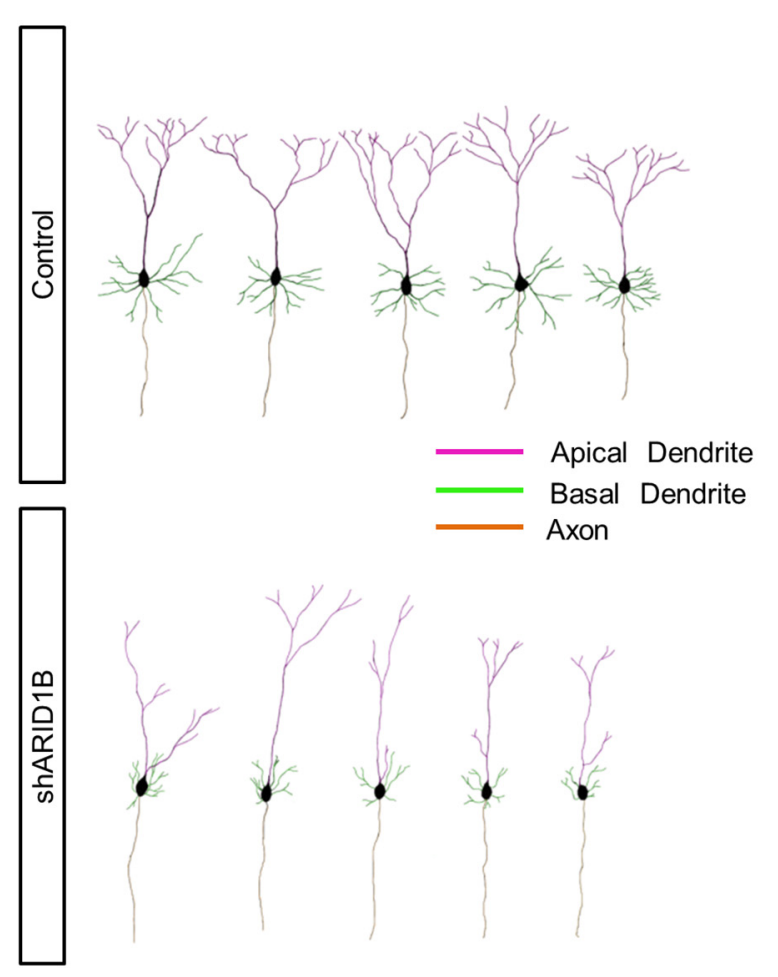

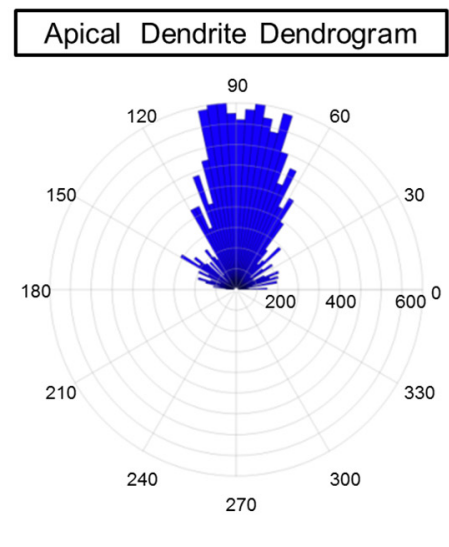

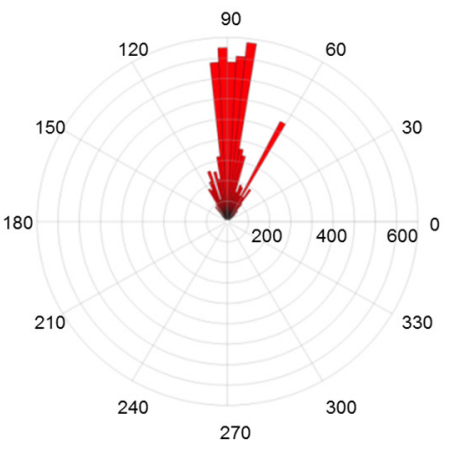

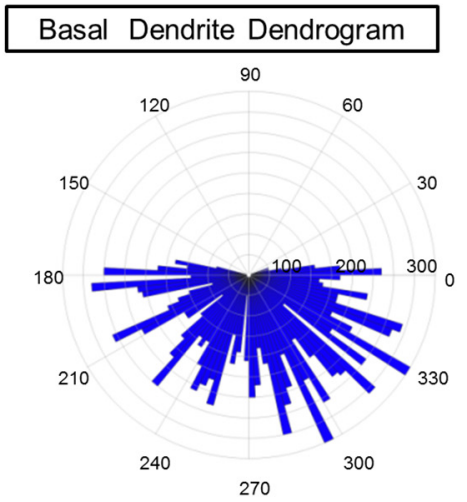

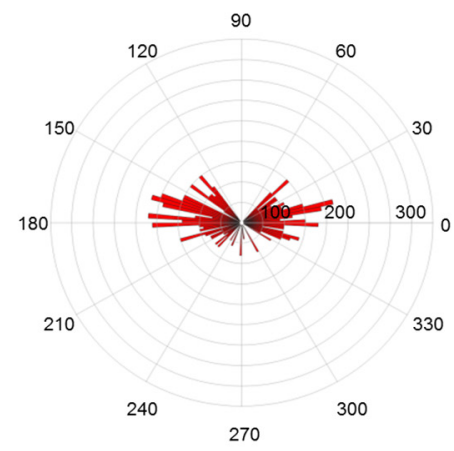

Figure 3. Dendritic orientation in ARID1B-deficient neurons. Quantification of apical and basal dendritic orientation in control and ARID1B-deficient neurons. Dendrograms show that basal dendrites extended more laterally $\left(0^{\circ}\right.$ and $\left.180^{\circ}\right)$ and were shorter in ARID1B-deficient neurons compared with control neurons. Apical dendrites were distinctly oriented toward the pial surface $\left(90^{\circ}\right)$. The numbers on the outer circle indicate the degrees of angles from the right horizontal line. The numbers inside of the outer circle show the lengths of dendrites. $n=20$ cells from five mice for control, and $n=18$ cells from five mice for shARID1B.

neurons generally extended basal dendrites laterally and toward the ventricular zone (Fig. 3). However, basal dendrites of ARID1B-deficient neurons were oriented more laterally, compared with control basal dendrites. Additionally, ARID1Bdeficient basal dendrites were shorter than those of control neurons (Fig. 3). The orientation of apical dendrites did not appear to be different between control and ARID1B-deficient

\section{$\leftarrow$}

(Figure legend continued.) $\quad{ }^{* * *} p<0.001$. F, Dendritic arborization was examined at $\mathrm{P} 14$ after same experiments were performed, as in $\boldsymbol{C}$. Scale bar, $25 \mu \mathrm{m}$. G, Representative single-cell traces shown in $\boldsymbol{F}$. $\boldsymbol{H}$, Quantification of the numbers and lengths of dendrites. $n=76$ cells from five mice for control, and 72 cells from five mice for shARID1B. Statistical significance was determined by two-tailed Student's $t$ test. ${ }^{*} p<0.05,{ }^{* * *} p<0.001$. I, ARID1B deficiency inhibits dendritic arborization in dissociated neuronal culture. Primary neurons were isolated from E18.5 cerebral cortices, transfected with a control shRNA or shARID1B plasmid, and cultured for $7 \mathrm{~d}$ in the presence of AraC. Dendritic morphology was examined by immunostaining with a MAP2 antibody. Scale bars, $10 \mu \mathrm{m}$. J, Quantification of the number and length of dendrites. $n=86$ cells from three independent cultures for each condition (left two graphs). Cell type composition of AraC-treated culture was shown as the percentages of MAP2-positive neurons and GFAP-positive glial cells (right graph). Statistical significance was determined by two-tailed Student's $t$ test. ${ }^{* * *} p<0.001$. $\boldsymbol{K}$, Left, Sholl analysis of dendritic complexity in ARID1B-deficient neurons. The numbers of intersections of dendrites were counted on concentric circles distanced from the soma (middle panel). Right, The number of dendritic terminals. $L$, shmiRNA-mediated ARID1B knockdown inhibits dendritic arborization of pyramidal neurons in the developing cortex. A control shmiRNA or shmiARID1B construct was electroporated in utero into E14.5 mice, and dendritic arborization patterns were examined at P14. Scale bar, $25 \mu \mathrm{m}$. $M$, Representative traces of single cells shown in $\boldsymbol{L}$. $N$, Quantification of the number and length of dendrites. $n=78$ cells from five mice for each condition. Statistical significance was determined by two-tailed Student's t test. ${ }^{* *} p<0.01,{ }^{* * *} p<0.001 .0$, Coexpression of shARID1Bresistant mutant suppressed the inhibitory effect of shARID1B in dendritic growth. $\boldsymbol{P}$, Quantification of the number and length of dendrites. $n=40$ cells from five mice for each condition. Statistical significance was determined by two-tailed Student's $t$ test. ${ }^{* * *} p<0.001$. neurons. Most apical dendrites were oriented toward the pial surface. Together, these results reveal that ARID1B is required for normal dendritic arborization and the orientation of cortical pyramidal neurons during development.

We further examined dendritic arborization in layer I. Correct innervation of dendrites into layer I is important because this layer receives inputs from local inhibitory interneurons and longrange axons of subcortical regions, which is thought to be vital for cognitive processes (Shipp, 2007). After the electroporation of the control or shARID1B construct in utero at E14.5, the dendritic innervation pattern within layer I was examined in P14 brains. In control samples, dendritic tufts from layer II/III pyramidal neurons of the lateral cortex elaborated complex branches, filling up the layer (Fig. 4A). Furthermore, apical dendrites in layer I extended to the pial surface, which is shown by intense GFP staining along the pial surface in control brains (Fig. $4 A$, arrowheads). In contrast, there was a decrease in the outgrowth of ARID1Bdeficient dendrites into layer I. Dendrites contacting the pial surface were markedly reduced in ARID1B-deficient samples (Fig. $4 A$, arrowheads). We found a similar defect of dendritic elaboration of ARID1B-deficient neurons in the medial cerebral cortex (Fig. 4B). The numbers of dendritic arbors contacting the pial surface (shARID1B: $24.9 \pm 3$; control: $108.3 \pm 4 ; p=0.000182$ ) as well as apical dendrites in the marginal zone (shARID1B: $83.2 \pm 3$; control: $110.9 \pm 8 ; p=0.036906$ ) were reduced by $77 \%$ and $25 \%$, respectively, in shARID1B-electroporated brain samples (Fig. 4C). Measurements of GFP intensities within layer I (shARID1B: $0.63 \pm 0.03$ A.U.; control: $1.0 \pm 0.04$ A.U.; $p=$ 0.008087 ) and alongside the pia (shARID1B: $0.36 \pm 0.02$ A.U.; control: $1.0 \pm 0.03$ A.U.; $p=0.000199$ ) confirmed the decreased dendritic elaboration of ARID1B-deficient neurons. 
A
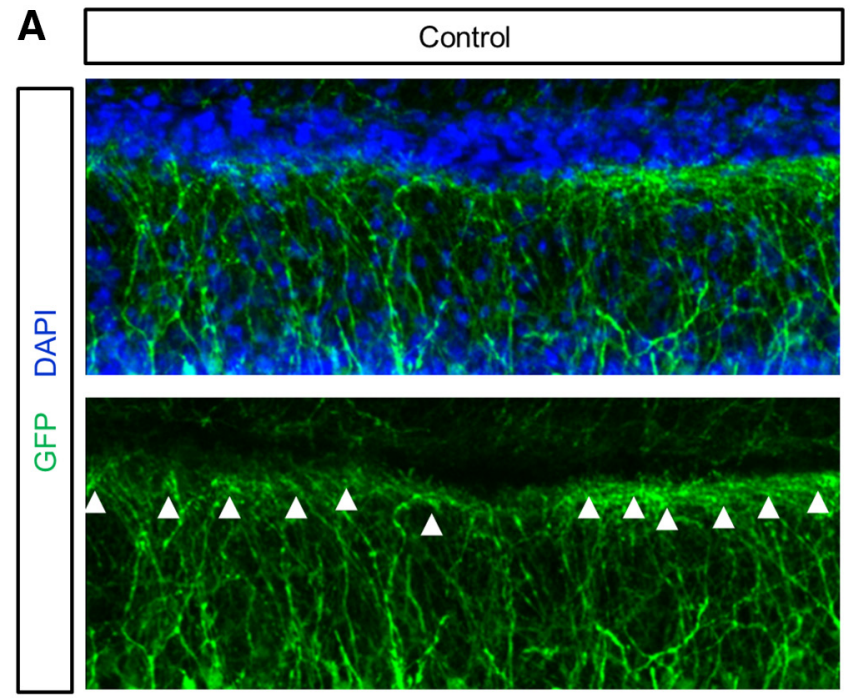

\section{B}

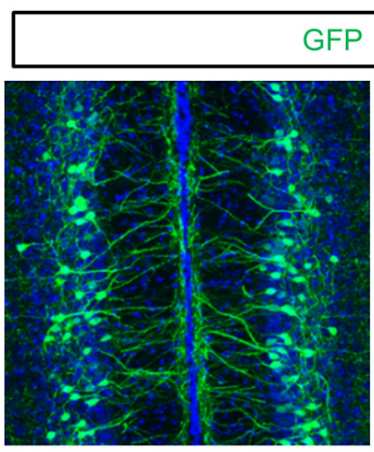

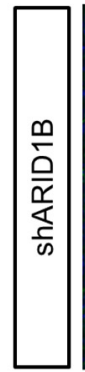

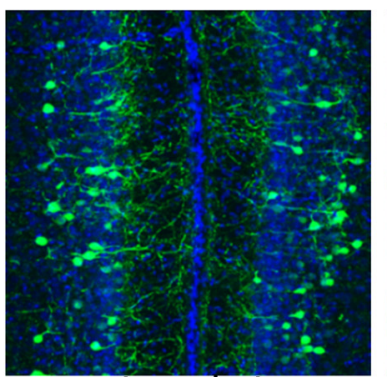

$\equiv|-| \stackrel{\varpi}{\bar{a}}|-| \equiv$
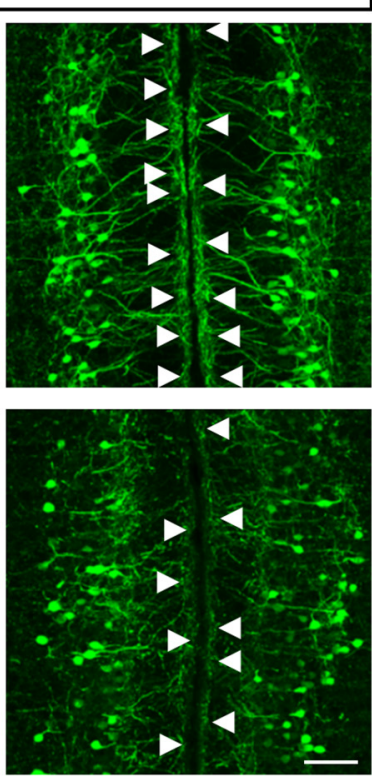
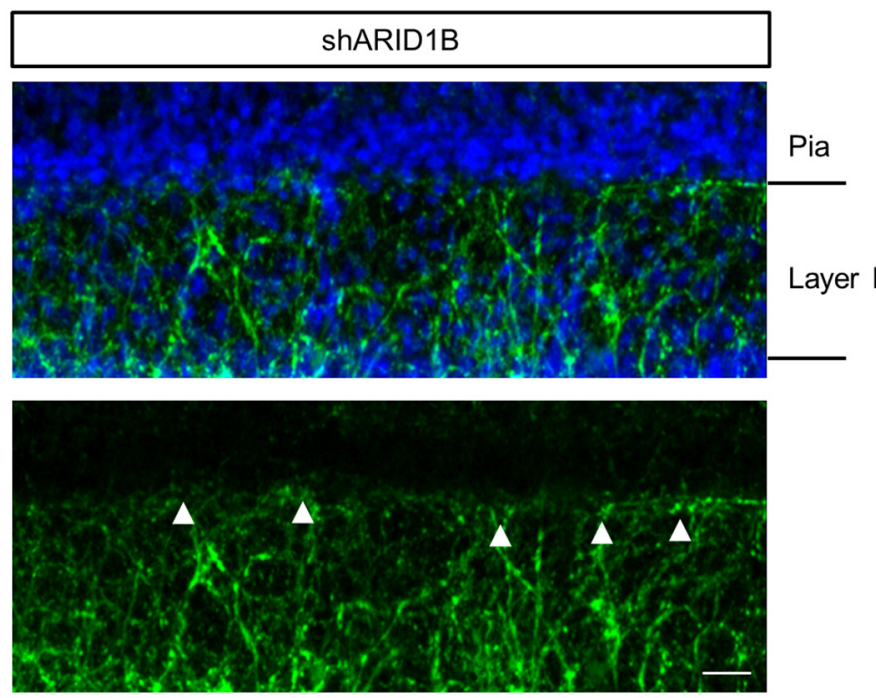

C

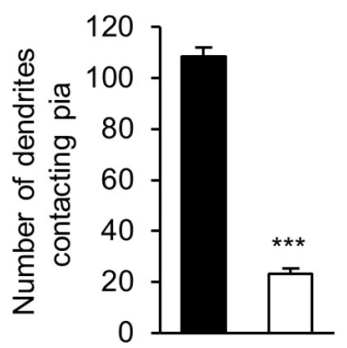

Control
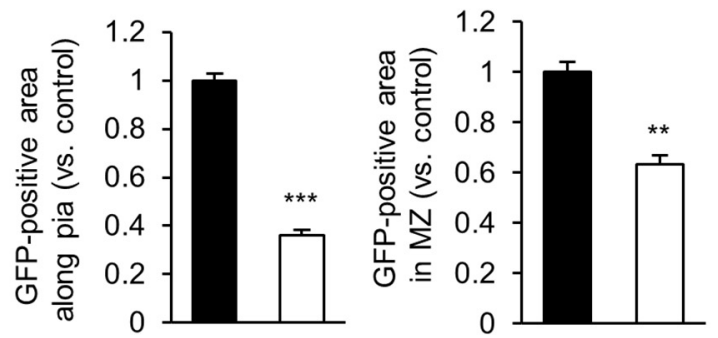

Figure 4. ARID1B deficiency suppresses dendritic outgrowth into layer I.A, Dendritic extension patterns of ARID1B-deficient neurons. Control shRNA or shARID1B was electroporated in utero into E14.5 embry0s, and dendritic innervation was assessed in layer I of P7 brains. Apical dendrites of ARID1B-deficient neurons innervated into the layer markedly less than control dendrites. Arrowheads show the pial areas where dendritic tufts of control or ARID1B-deficient neurons made contacts and elaborated branches. Scale bar, $10 \mu \mathrm{m}$. $\boldsymbol{B}$, Images taken from the same brain samples as in $\boldsymbol{A}$ showed dendritic morphologies in layer I of medical cerebral cortex. Scale bar, $50 \mu \mathrm{m}$. C, Quantification of dendritic innervation in layer I. The GFP-positive areas, the numbers of dendritic fibers, the numbers of fibers contacting the pial surface, and the GFP intensity alongside the pia were measured using ImageJ. Twenty sections from five mice for each condition were analyzed. Statistical significance was determined by two-tailed Student's t test. ${ }^{*} p<0.05,{ }^{* *} p<0.01$, ${ }^{* * *} p<0.001$.

\section{ARID1B regulates dendritic development of}

hippocampal neurons

For the establishment of functional hippocampal circuitry, neurons in the hippocampus need to be connected through dendrites and axons during brain development. We showed that ARID1B is required for dendritic arborization of cortical neurons. These findings strongly suggest that this protein carries similar roles during hippocampal development. To examine this possibility, we decided to eliminate the ARID1B gene in hippocampal pyramidal neurons using an in utero electroporation with a modification that features a different orientation of electrodes compared with cortical neuron targeting (Fig. 5A). Using this technique, we delivered shARID1B into the lower medial cortex of E14.5 mouse brains, which forms the hippocampus at later developmental stages. Then, ARID1B knockdown effects were assessed in P14 brain samples. We investigated the dendritic arborization of hippocampal pyramidal neurons in control and shARID1Belectroporated neurons. Control neurons developed complex apical and basal dendrites with multiple branches (Fig. $5 B, C$ ); however, ARID1B-deficient cells generated few dendritic branches. We found that the numbers of secondary and tertiary dendrites as well as primary and total dendrites were reduced in ARID1B-deficient neurons. Particularly, there were $62 \%$ and 92\% decreases in secondary dendrites (shARID1B: $1.6 \pm 0.2$; 
A

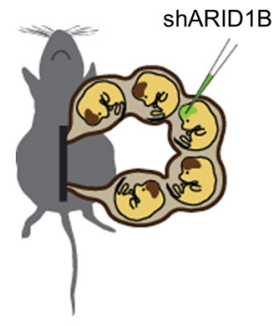

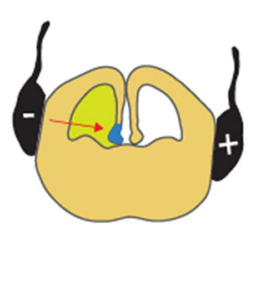

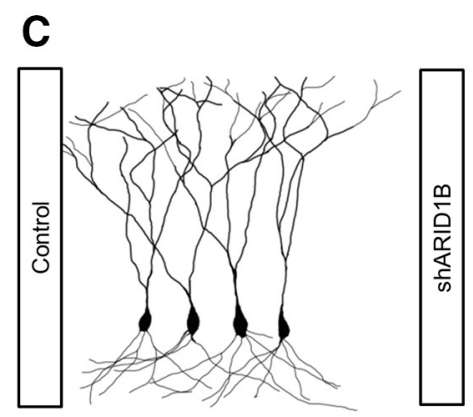

D
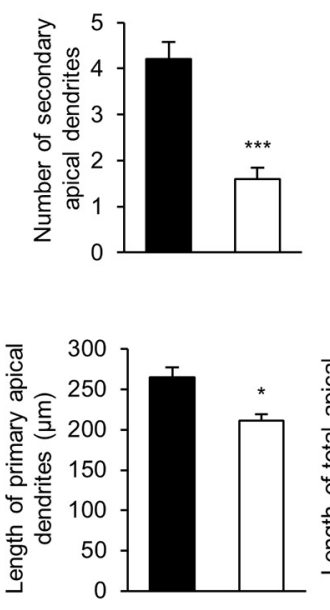

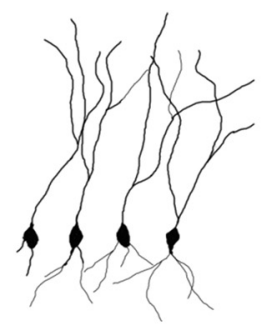

Control $\square$ shARID1B
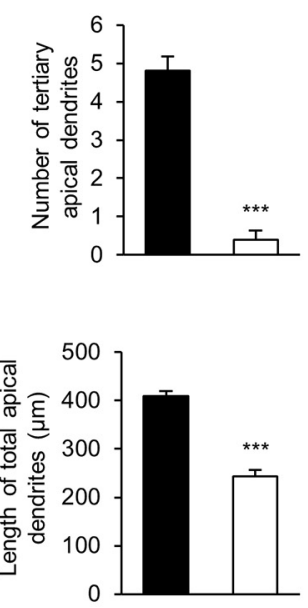
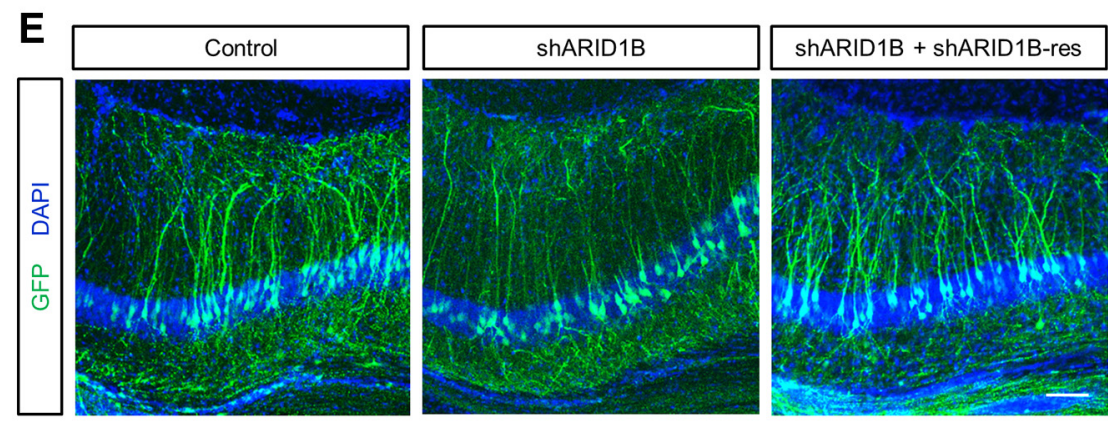

Control

$\square$ shARID1B

ShARID1B

shARID1B-resistant

$\mathbf{F}$
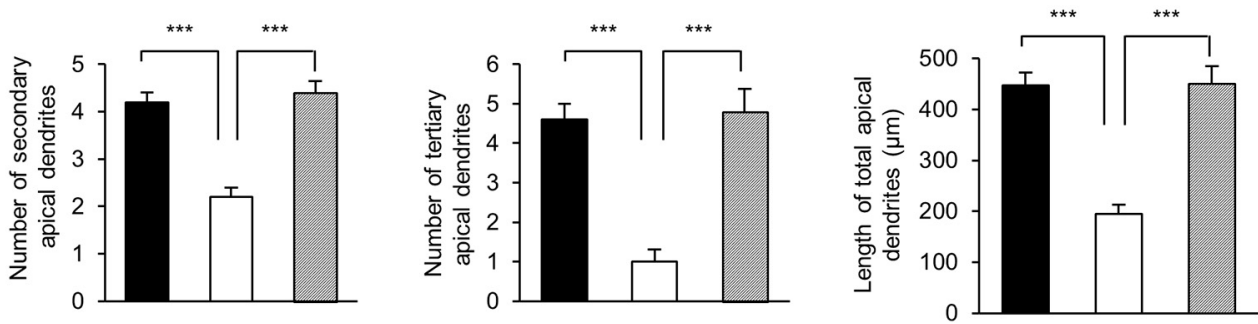

Figure 5. ARID1B inactivation results in abnormal hippocampal neuron development. $A$, A schematic illustration of gene targeting in the developing hippocampus. Genes are injected into a hemisphere and electroporated in utero. Forceps-type electrodes are placed to generate shocks toward the unfolded hippocampal sulcus near cortical hem in the medial cortex (blue), which eventually becomes dentate gyrus and cornu ammonis at later developmental stages. $\boldsymbol{B}$, Control shRNA or shARID1B plasmid was electroporated in utero into E14.5 mouse embryos, as described in A. GFP-positive pyramidal neurons in P14 hippocampal CA1 region were visualized. Arborization of dendrites was suppressed when ARID1B was eliminated. Scale bar, $25 \mu \mathrm{m}$. C, Representative single-cell traces showing dendritic morphologies of control and shARID1B-electroporated hippocampal neurons. D, Quantification of lengths and numbers of dendrites in control and ARID1Bdeficient cells. $n=75$ cells from five mice for control, and 69 cells from five mice for shARID1B. Statistical significance was determined by two-tailed Student's t test. ${ }^{*} p<0.05,{ }^{* * *} p<0.001$. $E$, Coexpression of the shARID1B-resistant mutant suppressed the inhibitory effect of shARID1B in hippocampal dendritic growth. $\boldsymbol{F}$, Quantification of the number and length of dendrites. $n=40$ cells from five mice for each condition. Statistical significance was determined by two-tailed Student's $t$ test. ${ }^{* * *} p<0.001$. 
A
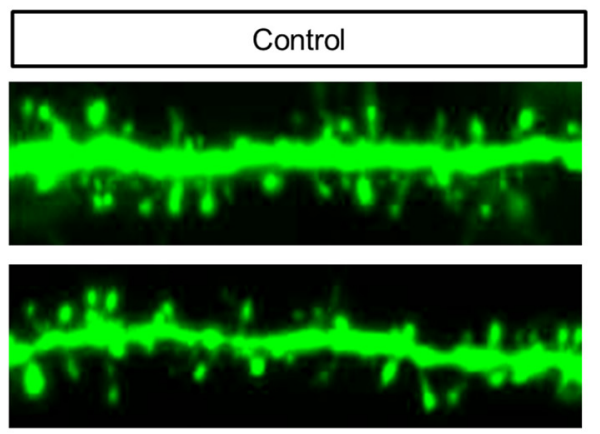
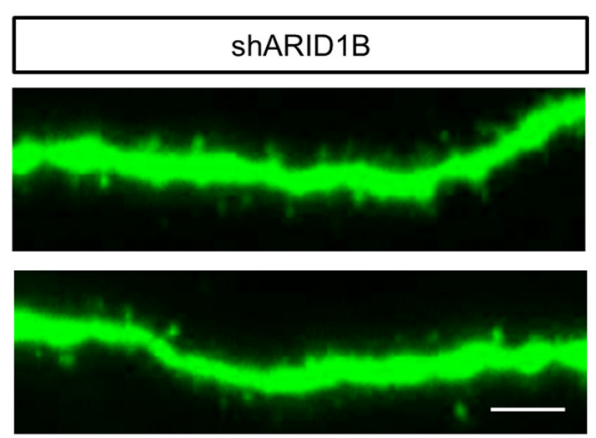

B

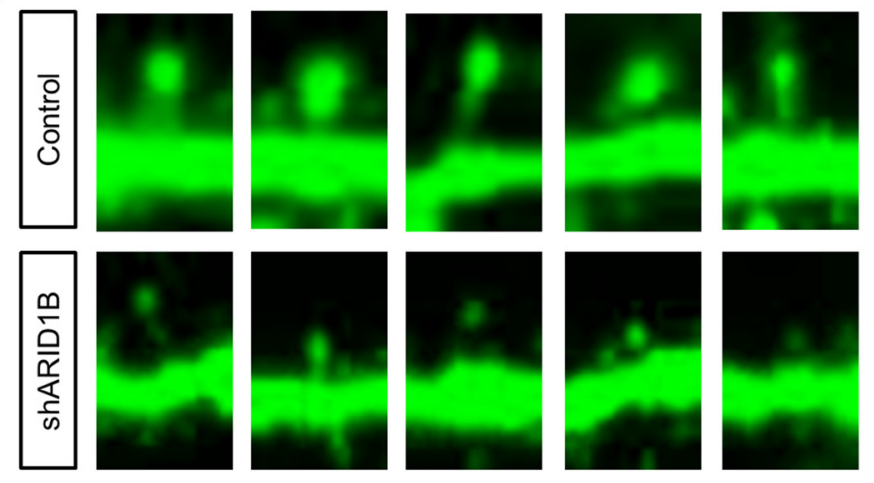

C
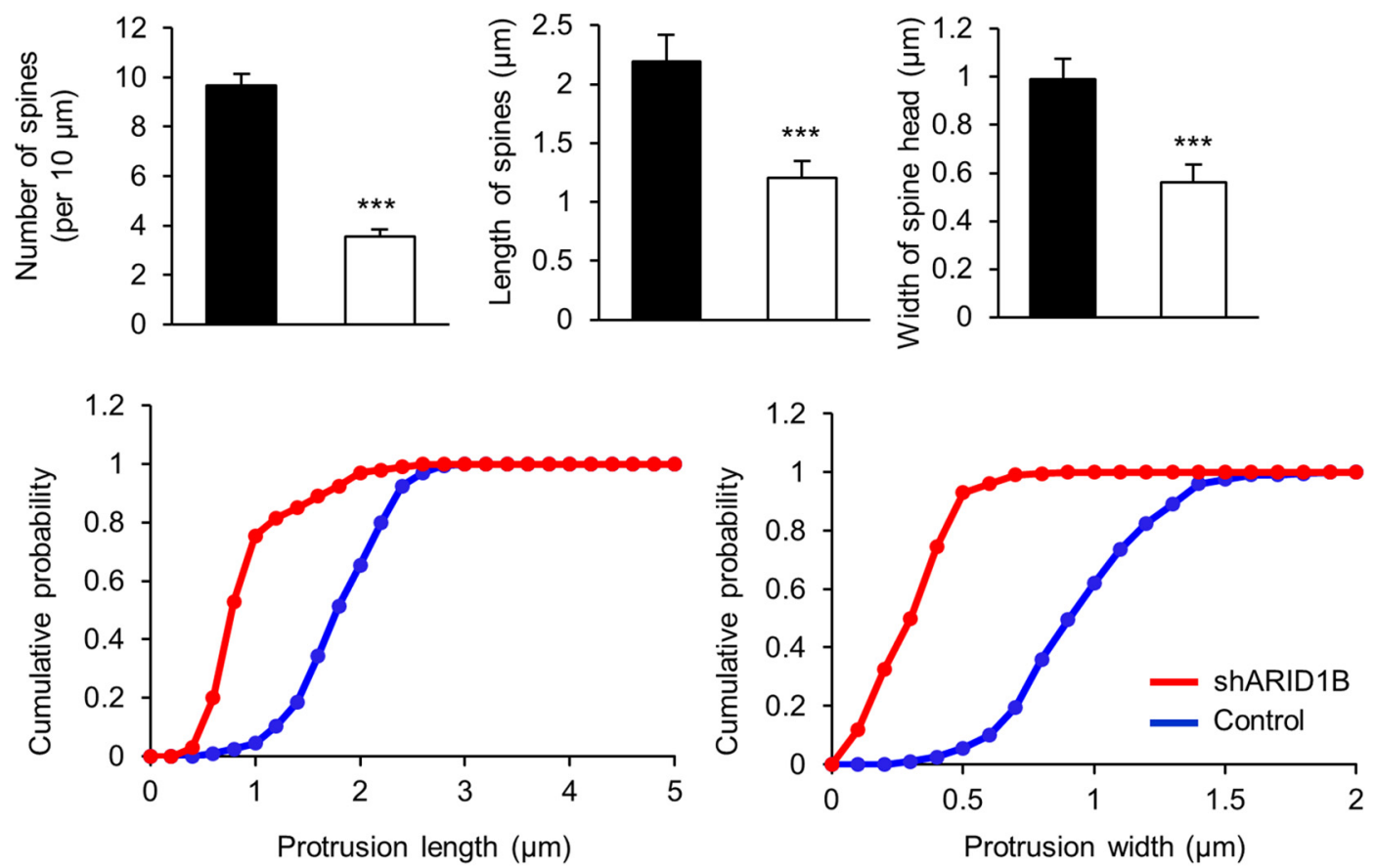

Figure 6. Elimination of ARID1B leads to abnormal formation of dendritic spines. A, Spine morphology of neurons expressing shARID1B in vivo. Embryonic mice at E14.5 were electroporated with a control shRNA or shARID1B construct in utero. At P40, brains were collected and sliced for the assessment of spine morphology. Spines of cortical pyramidal neurons were examined by confocal microscopy. Compared with controls, ARID1B-deficient neurons developed fewer and shorter spines. Scale bar, $5 \mu \mathrm{m}$. B, Higher-magnification images of dendritic spines. C, Quantification of spine development. Numbers, lengths, and head sizes of spines were examined. $n=33$ cells and 883 spines from five mice for control, and 39 cells and 352 spines from five mice for shARID1B. Statistical significance was determined by two-tailed Student's $t$ test. ${ }^{* *} p<0.001$.

control: $4.2 \pm 0.4 ; p=0.000399)$ and tertiary dendrites (shARID1B: $0.4 \pm 0.1$; control: $4.8 \pm 0.4 ; p<0.0001$ ) in ARID1B-deficient neurons, respectively (Fig. $5 D$ ). The lengths of primary apical dendrites (shARID1B: $211 \pm 8 \mu \mathrm{m}$; control:
$265 \pm 12 \mu \mathrm{m} ; p=0.01819)$ and total apical dendrites (shARID1B: $243 \pm 13 \mu \mathrm{m}$; control: $410 \pm 11 \mu \mathrm{m} ; p=0.000140$ ) were also significantly decreased when ARID1B was eliminated in the hippocampal neurons. To confirm the shARID1B effect on 
A

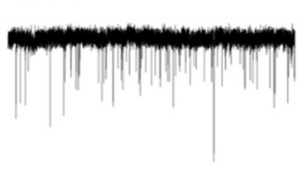

B

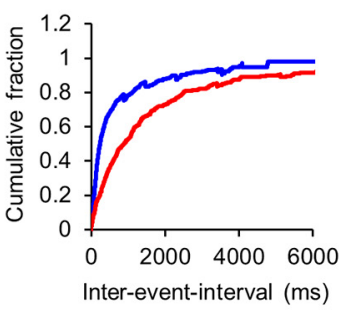

C

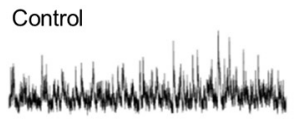

D

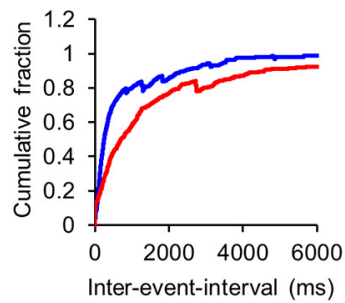

E

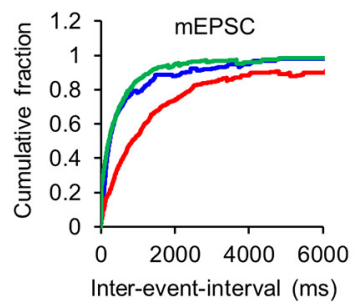

$\mathbf{F}$
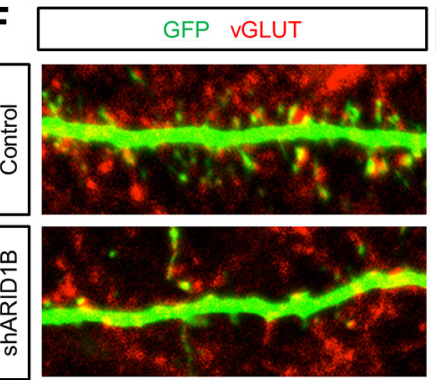

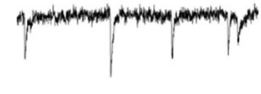

ShARID1B
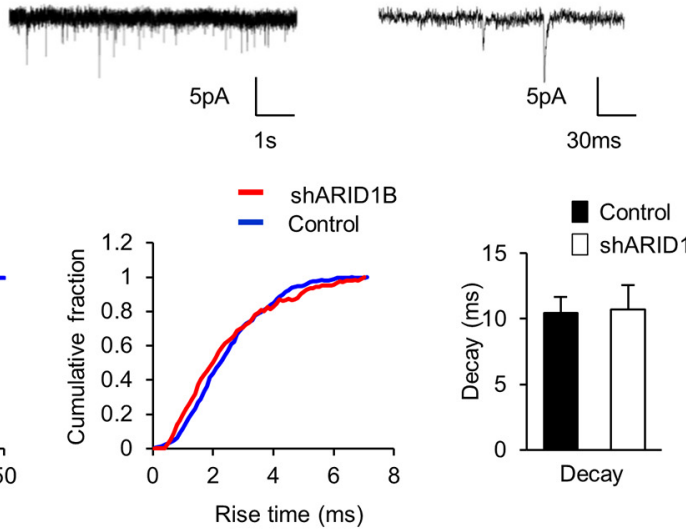

shARID1B
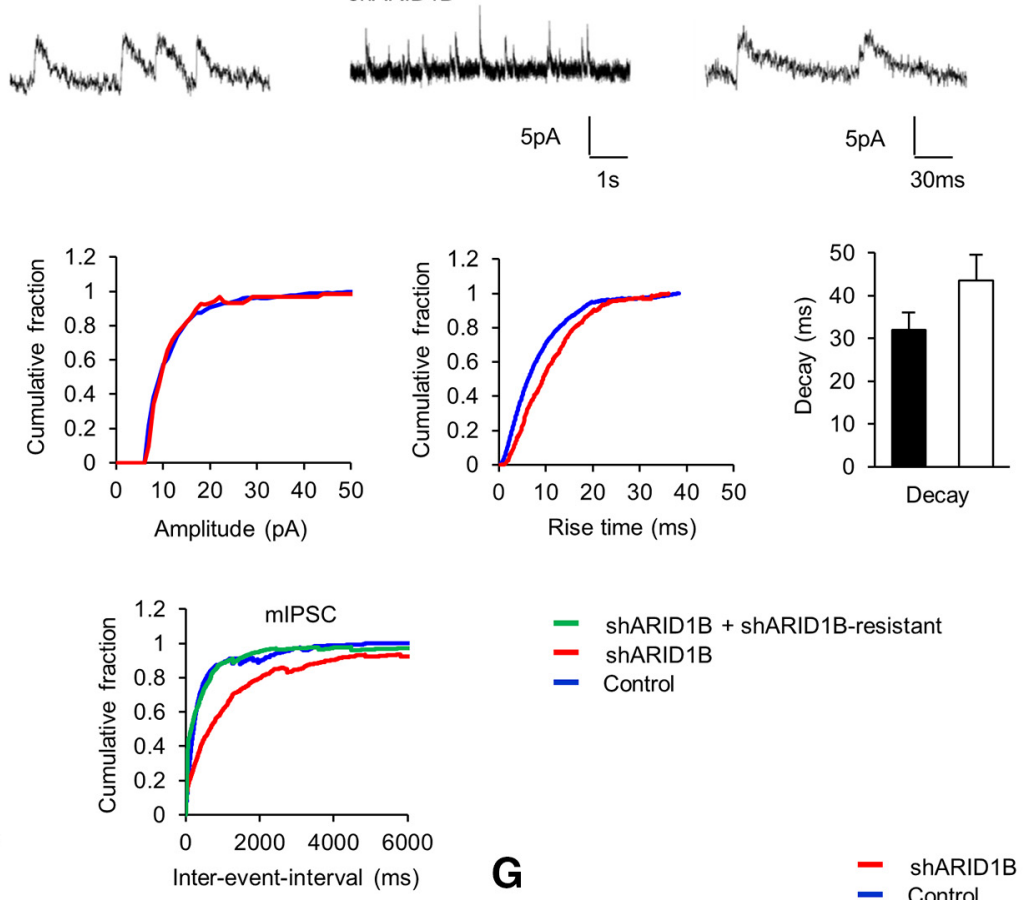
- shARID1B + shARID1B-resistan
- shARID1B

- Control

G
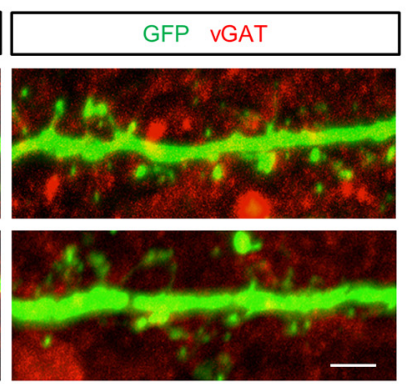

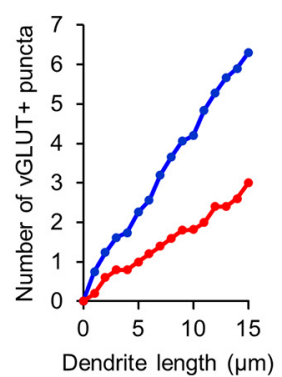

Dendrite length $(\mu \mathrm{m})$
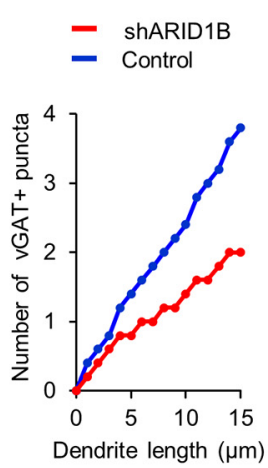

Figure 7. Altered excitatory and inhibitory synaptic transmission in ARID1B-deficient neurons. A, Representative whole-cell voltage-clamp recording showing mEPSCs as downward deflections from control and shARID1B-transfected neurons. Recordings were performed at $-70 \mathrm{mV}$. Data were filtered at $2 \mathrm{kHz}$ ( $1 \mathrm{kHz}$ for presentation) and digitized at $20 \mathrm{kHz}$. B, The interevent interval of mEPSCs was increased in ARID1B-deficient neurons compared with controls (left graph). Amplitude, rise time, or decay of currents was not changed (middle graphs). $n=9$ cells for each condition from three independent cultures using three mice. C, Representative whole-cell voltage-clamp recording showing mIPSCs as upward deflections from control and shARID1B-transfected neurons. Recordings were performed at $0 \mathrm{mV}$. Data were filtered at $2 \mathrm{kHz}$ ( $1 \mathrm{kHz}$ for presentation) and digitized at $20 \mathrm{kHz}$. D, A significantly increased interevent interval in mIPSCs was observed in ARID1B-deficient neurons. No differences in the amplitude or decay of currents were observed. $n=8$ cells for each condition from three independent cultures using three mice. Statistical significance was determined by two-tailed Student's $t$ test. ${ }^{*} p<0.05,{ }^{* *} p<0.01 . E$, Coexpression of the shARID1B-resistant construct inhibited the shARID1B effect. $F$, ARID1B knockdown reduces the number of excitatory and inhibitory synapses. Cortical neurons from E18.5 mice were cultured for $14 \mathrm{~d}$ after transfecting them with control shRNA or shARID1B. Excitatory and inhibitory synapses were assessed by immunostaining with vGlut 1 and vGAT antibodies. Scale bar, $5 \mu \mathrm{m}$. G, Quantification of synaptic numbers shown in $\boldsymbol{F} . n=40$ cells from three independent cultures using three mice for each condition. Statistical significance was determined by two-tailed Student's $t$ test. ${ }^{*} p<0.05,{ }^{* * *} p<0.001$. 
A

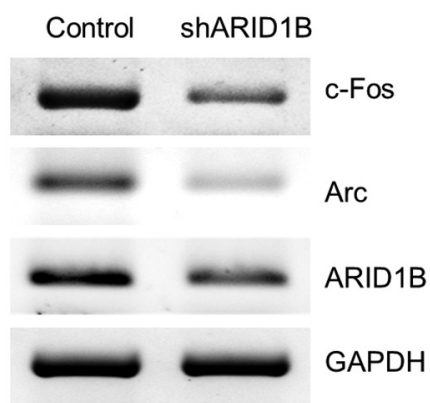

C

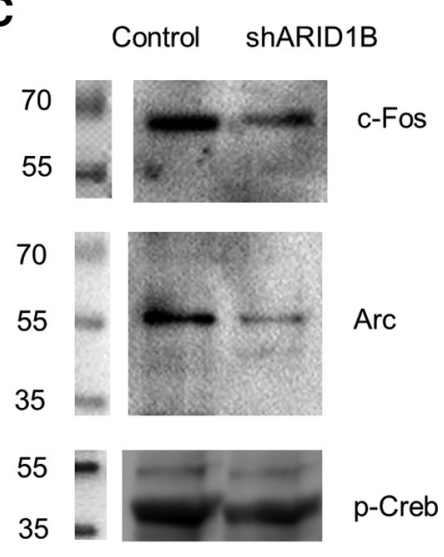

E

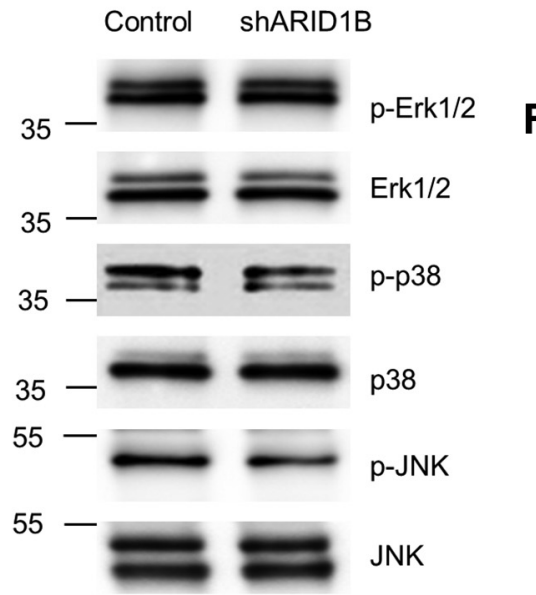

G

Control shARID1B

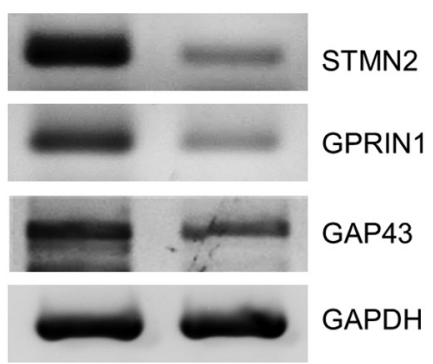

B

Control
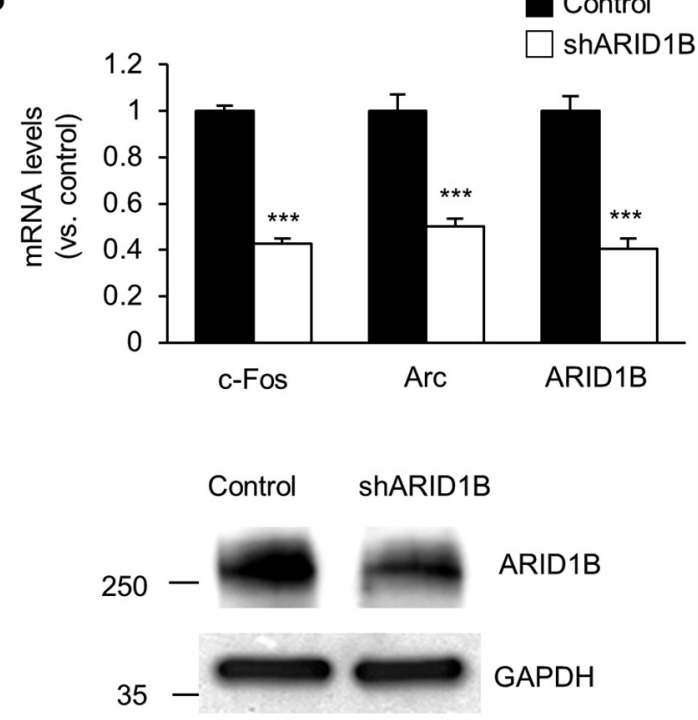

D

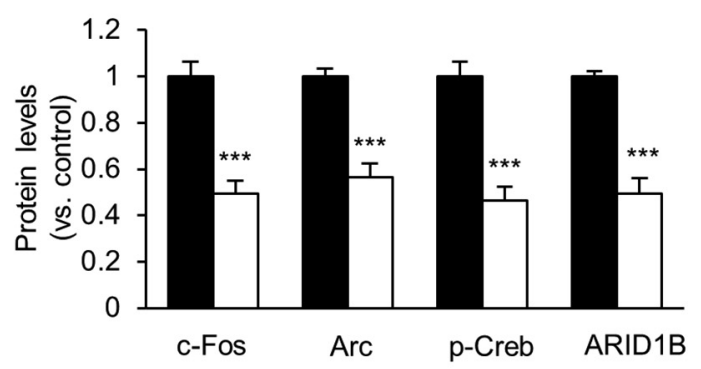

F

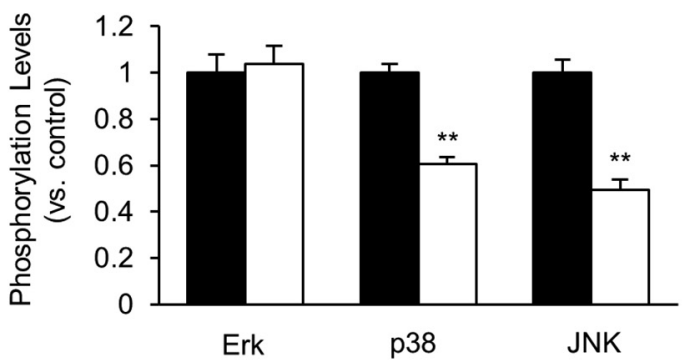

H

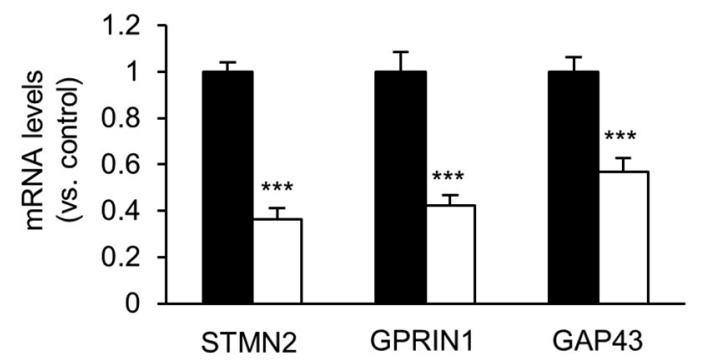

Figure 8. Effects of ARID1B knockdown on gene expression. A, Elimination of ARID1B decreases the transcript level of C-Fos and Arc. Cortical neurons from E16.5 mice were cultured and infected with a lentivirus encoding ARID1B shRNA (pLVX-shARID1B). Cellular lysates from the cultures were subjected to RNA isolation and RT-PCR. B, Quantification of $A$. The relative levels of the genes were normalized to GAPDH expression. The band intensities were measured using ImageJ. $n=3$ independent cortical cultures using three mice. Statistical (Figure legend continues.) 
hippocampal dendrites, we electroporated control, shARID1B, or shARID1B and the shARID1B-resistant construct into the hippocampus at E14 in utero, and assessed dendritic morphology at P14. We found that coexpression of the shARID1B-resistant mutant rescued the abnormal dendritic morphology caused by shARID1B in the hippocampus. The length of apical dendrites in cells coexpressing shARID1B and the shARID1B-resistant construct was increased compared with shARID1B alone, and was similar to the length of control dendrites (control: $447 \pm 26 \mu \mathrm{m}$; shARID1B: $194 \pm 19 \mu \mathrm{m}$; shARID1B/shARID1B-resistant: $451 \pm 33 \mu \mathrm{m} ; p<0.0001$ between shARID1B and shARID1B/ shARID1B-resistant dendrites). The numbers of secondary apical dendrites (control: $4.2 \pm 0.2$; shARID1B: $2.2 \pm 0.2$; shARID1B/ shARID1B-resistant: $4.4 \pm 0.3 ; p=0.000117$ between shARID1B and shARID1B/shARID1B-resistant) and tertiary apical dendrites (control: $4.6 \pm 0.4$; shARID1B: $1.0 \pm 0.3$; shARID1B/ shARID1B-resistant: $4.8 \pm 0.6 ; p=0.000439$ between shARID1B and shARID1B/shARID1B-resistant) were also increased (Fig. 5E,F). Together, our results demonstrate the requirement of ARID1B for dendritic arborization in the developing hippocampus.

\section{ARID1B is required for normal development of dendritic spine and synaptic transmission}

Dendritic spines are the sites of synaptic contacts and, therefore, are the basis of synaptic circuitry. We examined whether ARID1B plays a role in dendritic spine formation. After in utero electroporation of control or shARID1B, dendritic spines of cortical pyramidal neurons were examined at P42. We found that ARID1B-deficient neurons generated fewer and shorter spines compared with controls (Fig. 6A,C). Compared with controls, the number and length of spines, respectively, were decreased by 65\% (shARID1B: 3.4 and $10 \pm 0.5 \mu \mathrm{m}$; control: 9.8 and $10 \pm 0.4$ $\mu \mathrm{m} ; p<0.0001$ ) and by 45\% (shARID1B: $1.2 \pm 0.2 \mu \mathrm{m}$; control: $2.2 \pm 0.3 \mu \mathrm{m} ; p<0.0001)$ in ARID1B-deficient neurons. The abnormal spines appeared as short filopodia that were not fully developed to form spine heads (Fig. 6B). Accordingly, the size of the spine head was reduced by $43 \%$ in ARID1B-deficient neurons (shARID1B: $0.25 \pm 0.02 \mu \mathrm{m}$; control: $0.75 \pm 0.06 \mu \mathrm{m} ; p<$ 0.0001 ; Fig. $6 B, C)$. Given that the abnormal formation of dendritic spines is associated with the pathology of intellectual disability, these findings suggest that ARID1B deficiency causes intellectual disability at least in part via disrupting spine morphogenesis. Our data demonstrate that ARID1B plays essential roles in dendritic spine development in cortical projection neurons.

Next, we examined the functional relevance of the abnormal morphogenesis of dendrites and spines in ARID1B-deficient neurons. We asked whether ARID1B knockdown affects excitatory and inhibitory neurotransmission. Whole-cell recordings

\footnotetext{
$\leftarrow$

(Figure legend continued.) significance was determined by two-tailed Student's $t$ test. ${ }^{* * *} p<0.001$. C, Western blotting was performed to measure the protein levels of c-Fos, Arc, and $p$-CREB in control and ARID1B-deficient neurons. D, Quantification of protein levels shown in $C$. $n=3$ independent cortical cultures using three mice. Statistical significance was determined by two-tailed Student's $t$ test. ${ }^{* *} p<0.001$. $E$, Phosphorylation levels of ERK1/2, p38, and JNK in control and ARID1B-deficient neurons were assessed by Western blotting. $\boldsymbol{F}$, Quantification of phospho-protein levels shown in $\boldsymbol{E}$. The relative levels of phospho-proteins were normalized to total protein levels. $n=3$ independent cortical cultures using three mice. Statistical significance was determined by two-tailed Student's $t$ test. ${ }^{* *} p<0.01$. G, ARID1B deficiency decreases the levels of neurite growth-associated transcripts. $\boldsymbol{H}$, Quantification of $\boldsymbol{G}$. $n=3$ independent cortical cultures using three mice. Statistical significance was determined by two-tailed Student's $t$ test. ${ }^{* * *} p<0.001$.
}

from neurons transfected with either control or shARID1B were performed. The neurons were visualized by GFP expression. We observed an increase in the interevent interval of mEPSCs from ARID1B-deficient neurons $(p<0.0001$, Kolmogorov-Smirnov test; Fig. $7 A, B$ ). But, the amplitude (shARID1B: $11.74 \pm 1.8 \mathrm{pA}$; control: $11.08 \pm 1.0 \mathrm{pA} ; p=0.76705$ ), rise time (shARID1B: $2.295 \pm 0.27 \mathrm{~ms}$; control: $2.435 \pm 0.21 \mathrm{~ms} ; p=0.4235$ ), or decay (shARID1B: $10.72 \pm 1.8 \mathrm{~ms}$; control: $10.45 \pm 1.2 \mathrm{~ms} ; p=$ 0.90545) of mEPSCs was not significantly changed. Together with dendritic morphology data, these results suggest that ARID1B is necessary for the development of excitatory synapses. We further tested whether ARID1B selectively affects excitatory or inhibitory synapses by recording mIPSCs in the presence of NBQX and D-AP5. We found that the mIPSC interevent interval was also increased in ARID1B-deficient neurons $(p<0.0001$, Kolmogorov-Smirnov test; Fig. 7C,D). To confirm the ARID1B knockdown effect, we measured the interevent interval of mEPSCs and mIPSCs after we transfected shARID1B with the shARID1B-resistant construct (Fig. 7E). We found that coexpression of the shARID1B-resistant construct rescued the abnormal interevent interval caused by shARID1B. The increase in the interevent interval of the mEPSC and MIPSC was to a similar extent, suggesting that ARID1B plays a critical role in the development/function of both excitatory and inhibitory synapses. The increased interevent interval of mEPSCs and mIPSCs suggests that ARID1B knockdown reduces the number of synapses. Thus, we examined whether ARID1B knockdown changes the number of excitatory and inhibitory synapses by immunostaining with antibodies to synaptic markers vGlutl (excitatory) and vGAT (inhibitory). We found that the numbers of excitatory and inhibitory synapses were reduced by $54 \%$ (shARID1B: $1.8 / 10 \pm 0.33$ $\mu \mathrm{m}$; control: $4.1 \pm 0.30 / 10 \mu \mathrm{m} ; p=0.000617)$ and $48 \%$ (shARID1B: $1.13 \pm 0.24 / 10 \mu \mathrm{m}$; control: $2.17 \pm 0.22 / 10 \mu \mathrm{m} ; p=$ $0.00148)$, respectively, in shARID1B-expressing cells compared with control cells (Fig. $7 F, G$ ).

\section{ARID1B controls expression of genes that are associated with neural development}

ARID1B is a member of SWI/SNF chromatin remodeling complex that regulates gene expression (Ho and Crabtree, 2010). Thus, we investigated the expression levels of potential target genes of ARID1B in the developing brain. We used a lentivirusmediated shRNA system to knock down ARID1B in cultured cortical neurons. Using RT-PCR and Western blotting, we first measured the mRNA and protein levels of c-Fos and Arc. ARID1B knockdown decreased the levels of c-Fos and Arc mRNA by $57 \%$ (shARID1B: $0.43 \pm 0.02$ A.U.; control: $1 \pm 0.01$ A.U.; $p<$ $0.0001)$ and 50\% (shARID1B: $0.50 \pm 0.02$ A.U.; control: $1 \pm 0.07$ A.U.; $p=0.000454$ ), respectively (Fig. $8 A, B$ ). Similarly, protein levels of c-Fos and Arc were reduced by $51 \% \%$ (shARID1B: $0.49 \pm 0.02$ A.U.; control: $1 \pm 0.01$ A.U.; $p<0.0001)$ and $44 \%$ (shARID1B: $0.56 \pm 0.03$ A.U.; control: $1 \pm 0.01$ A.U.; $p<$ 0.0001), respectively, in ARID1B-deficient neurons (Fig. 8C,D). Furthermore, the phosphorylation of CREB that is an inducer of c-Fos and Arc (Saito et al., 2013) was decreased by 53\% (shARID1B: $0.47 \pm 0.01$ A.U.; control: $1 \pm 0.02$ A.U.; $p<0.0001$ ) in ARID1B-deficient cells. Next, we examined the activity of upstream kinases that can phosphorylate CREB. Phosphorylation levels of p38 and JNK were decreased by $39 \%$ (shARID1B: $0.61 \pm$ 0.01 A.U.; control: $1 \pm 0.03$ A.U.; $p=0.001087)$ and $51 \%$ (shARID1B: $0.49 \pm 0.04$ A.U.; control: $1 \pm 0.05$ A.U.; $p=$ 0.001087), respectively, in ARID1B-deficient cells, while phos- 
pho-ERK1/2 level was not changed (shARID1B: $1.04 \pm 0.04$ A.U.; control: $1 \pm 0.04$ A.U.; $p=0.600092$; Fig. $8 E, F)$.

These results suggest that ARID1B regulates c-Fos and Arc induction via p38/JNK-mediated activation of CREB. Finally, we examined the expression of genes associated with neurite development because of the important role of ARID1B in dendritic development. STMN2 functions in microtubule dynamics (Ravelli et al., 2004), and its expression level is reduced in patient and mouse models of Rett syndrome (Nectoux et al., 2010, 2012). Both GAP43 and GPRIN1 play important roles in neurite outgrowth (Skene, 1989; Nordman and Kabbani, 2012). We found that the mRNA levels of neurite-associated genes, such as STMN2, GPRIN1, and GAP43, were significantly downregulated after ARID1B knockdown by $64 \%$ (shARID1B: $0.36 \pm 0.04$ A.U.; control: $1 \pm 0.04$ A.U.; $p<0.0001$ ), 58\% (shARID1B: $0.42 \pm 0.07$ A.U.; control: $1 \pm 0.04$ A.U.; $p=0.000372$ ), and $42 \%$ (shARID1B: $0.58 \pm 0.05$ A.U.; control: $1 \pm 0.04$ A.U.; $p=$ 0.00063 ), respectively (Fig. $8 G, H$ ). Our results show that ARID1B controls the gene expression of c-Fos, Arc, and neuriteassociated genes in developing neurons, and suggest that the altered gene expression contributes to the abnormal development of ARID1B-deficient neurons.

ARID1B regulation of c-Fos and Arc expression suggests that ARID1B binds to c-Fos and Arc promoters. To test this idea, we performed ChIP assays with an ARID1B antibody followed by amplifying c-Fos and Arc promoter regions using PCR. We found that ARID1B indeed physically interacted with c-Fos and Arc promoters (Fig. 9A). A ChIP assay with an acetyl-histone H3 antibody was used as a positive control. Next, using ChIP-PCR assays, we examined whether ARID1B determines the binding strength of Brg1, which is an important regulator of transcription and is another component of the SWI/SNF complex (Wang et al., 1996; Trotter and Archer, 2008). ARID1B interaction with either c-Fos or Arc promoter was markedly decreased after ARID1B knockdown, indicating that the interaction is specific (Fig. $9 B, C)$. Brg1 also showed an interaction with c-Fos and Arc promoters. Importantly, ARID1B knockdown reduced the strength of the Brgl-c-Fos promoter interaction (Fig. 9B). A very similar pattern was found in Brg1-Arc promoter interaction. Band intensities of c-Fos and Arc promoters after ARID1B knockdown were decreased by $51 \%$ (shARID1B: $0.49 \pm 0.04$ A.U.; control: $1 \pm 0.07$ A.U.; $p=0.013927$ ) and 48\% (shARID1B: $0.52 \pm 0.06$ A.U.; control: $1 \pm 0.08$ A.U.; $p=0.037836$ ), respectively, compared with controls (Fig. 9C).

Finally, we tested whether the overexpression of c-Fos or Arc restores dendritic arborization in ARID1B-deficient neurons. We cultured cortical neurons and transfected them with a control shRNA, an shARID1B, a c-Fos plasmid, an shARID1B, and a c-Fos plasmid, or an shARID1B and an Arc plasmid. The expression of shARID1B reduced the number and length of dendrites (Fig. $9 D, E$ ). Importantly, the coexpression of c-Fos partially rescued the inhibitory effect of shARID1B in dendritic growth. The number and length, respectively, of dendrites were increased by 104\% (shARID1B: $2.0 \pm 0.3$; shARID1B/c-Fos: $4.1 \pm 0.4 ; p=$ 0.002027 ) and $115 \%$ (shARID1B: $67 \pm 3.4 \mu \mathrm{m}$; shARID1B/cFos: $144 \pm 4.5 \mu \mathrm{m} ; p<0.0001$ ), compared with those in neurons transfected with only shARID1B (Fig. 9E). Arc coexpression also led to a significant rescue in the number and length, respectively, of dendrites (shARID1B: $2.0 \pm 0.3$; shARID1B/Arc: $4.2 \pm 0.4$; $p=0.002027$; shARID1B: $67 \pm 3.4 \mu \mathrm{m}$; shARID1B/Arc: $143 \pm$ $8.1 \mu \mathrm{m} ; p<0.0001$; Fig. $9 D, E)$. The overexpression of either c-Fos or Arc itself led to no significant changes in the number of neurites compared with control shRNA expression alone (con- trol: $5.6 \pm 0.5 ;$ control/c-Fos: $6.4 \pm 0.5 ; p=0.29949$, control/Arc: $6.8 \pm 0.4 ; p=0.09435)$. These results suggest that $\mathrm{c}$-Fos and/or Arc expression may be associated with ARID1B function in dendritic differentiation. However, the lengths of neurites were increased by c-Fos or Arc expression alone [control: $170 \pm 8.3 \mu \mathrm{m}$; control/c-Fos: $221 \pm 9.3 \mu \mathrm{m}$ ( $p=0.001995)$; control/Arc: $236 \pm$ $10.4 \mu \mathrm{m}(p=0.000553)]$. Thus, the rescue of the shARID1B phenotype might also be caused by a nonspecific effect of c-Fos and Arc on dendritic complexity that masks the shRNA phenotype. Additionally, we coexpressed c-Fos and shARID1B in utero at E14.5, and assessed cortical dendrites at P14. Coexpression of c-Fos partially recovered the number (control: $5.4 \pm 0.4$; shARID1B: $1.6 \pm 0.2$; shARID1B/c-Fos: $4.6 \pm 0.5 ; p=0.000725$ between shARID1B and shARID1B/c-Fos) and the length (control: $392 \pm 17 \mu \mathrm{m}$; shARID1B: $190 \pm 24 \mu \mathrm{m}$; shARID1B/c-Fos: $333 \pm 13 \mu \mathrm{m} ; p=0.002138$ between shARID1B and shARID1B/ c-Fos) of dendrites compared with shARID1B expression itself (Fig. 9F, G).

\section{Discussion}

We demonstrate the role of ARID1B in dendritic arborization and synaptic development in the developing brain. Our findings suggest that ARID1B plays an important role in the establishment of cognitive circuitry by regulating dendritic complexity. Thus, the defective differentiation of pyramidal neurons induced by ARID1B deficiency may cause intellectual disability via insufficient reception of inputs and the subsequent generation of abnormal outputs.

Recent studies (Yan et al., 2008) have shown that ARID1B is expressed in embryonic stem cells, and that its expression is associated with the maintenance and differentiation of these cells. However, there has been no information available about the expression pattern of embryonic and postnatal brains in which neurons find their destination and establish functional connections in the brain. We found that ARID1B is strongly expressed in differentiated neurons in the developing and postnatal mouse brains. These results suggest that ARID1B is involved in neuronal differentiation and maturation in mammalian brains. Indeed, using an in utero gene delivery strategy, we demonstrated that ARID1B is required for developing pyramidal neurons to generate a complex dendritic architecture. It is important to note that abnormalities in dendritic arborization are linked to the pathology of intellectual disability (Huttenlocher, 1974; Machado-Salas, 1984; Kaufmann and Moser, 2000). For example, abnormalities in the dendritic morphology of cortical neurons are identified from postmortem brain samples obtained from individuals with intellectual disability (Huttenlocher, 1974). Furthermore, the decreased complexity of dendritic branching in cortical pyramidal neurons is found in human brains from individuals with Rett syndrome (Belichenko et al., 1994; Armstrong, 2005). Similarly, in MeCP2 mouse models of intellectual disability, there are significant reductions in cortical dendritic branching and spines (Fukuda et al., 2005; Jentarra et al., 2010; Calfa et al., 2011; Samaco and Neul, 2011; Jiang et al., 2013). Interestingly, the abnormal dendrites of ARID1B-deficient pyramidal neurons phenocopy the dendritic morphology of the unbranched apical shafts in a MeCP2 mutant mouse (Jentarra et al., 2010). Thus, problems in establishing dendritic complexity appear to play a key role for the pathogenesis of ARID1B-associated intellectual disability. Chromatin remodeling is associated with dendritic differentiation (Wu et al., 2007; Yoo et al., 2009; Vogel-Ciernia et al., 2013). BAF53a and BAF53b, components 
A

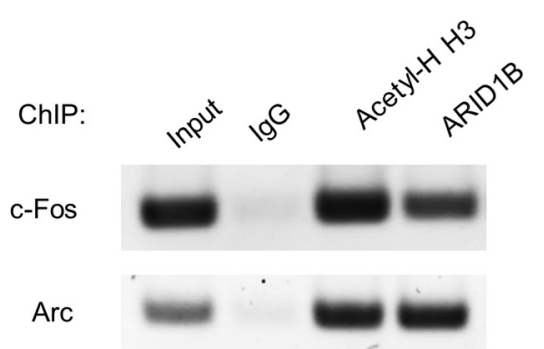

B
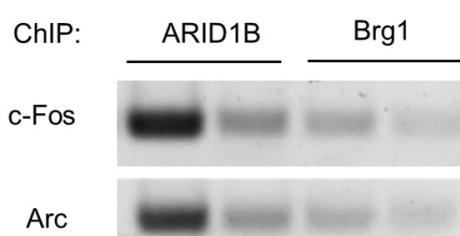

Arc

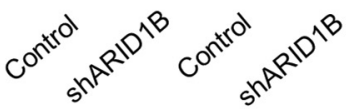

D
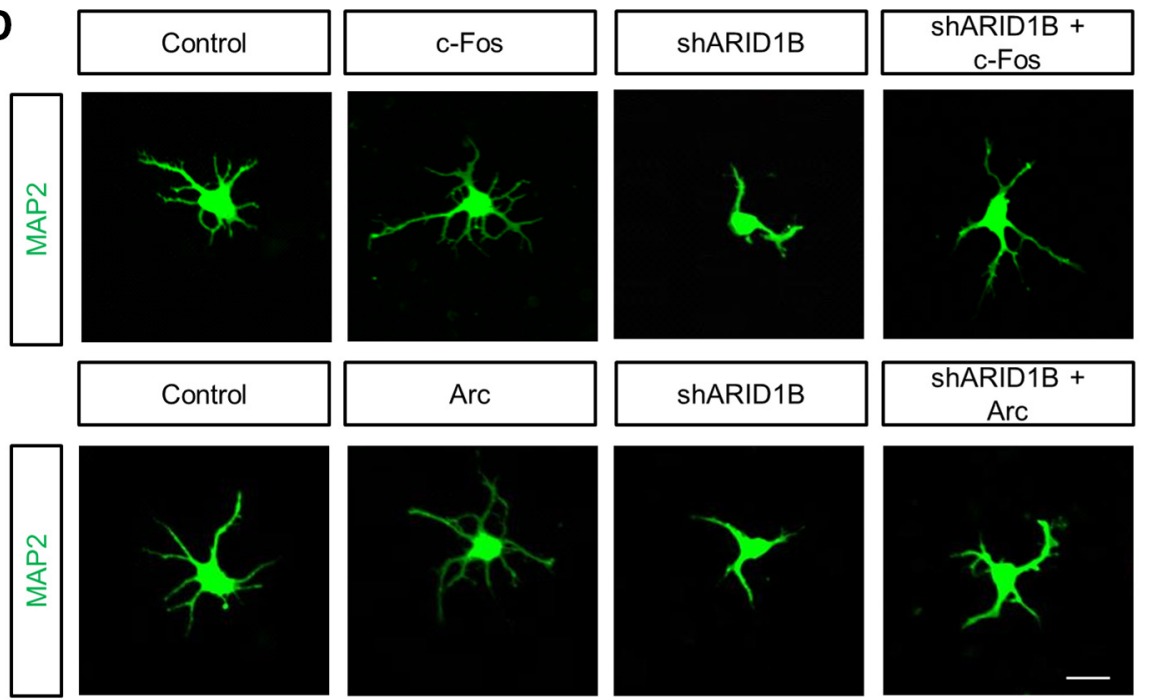

C

Control

$\square$ shARID1B
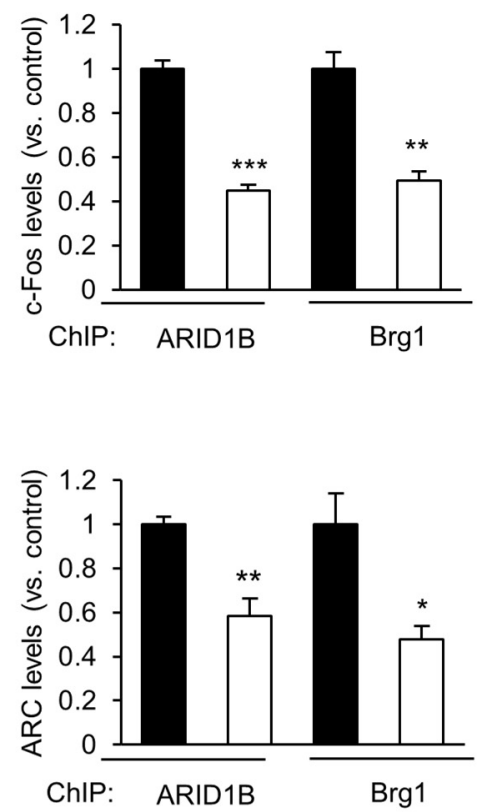

E
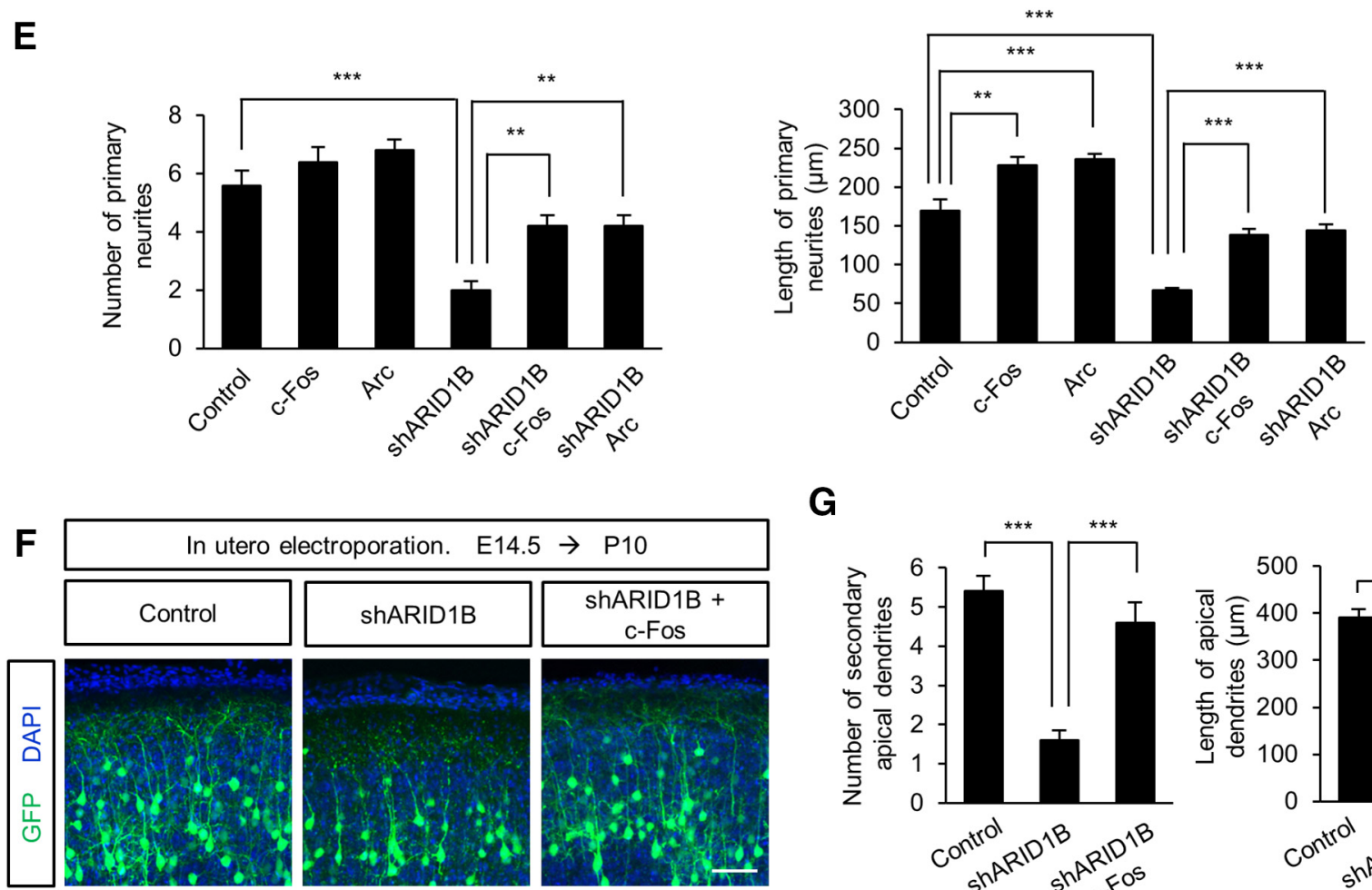

G
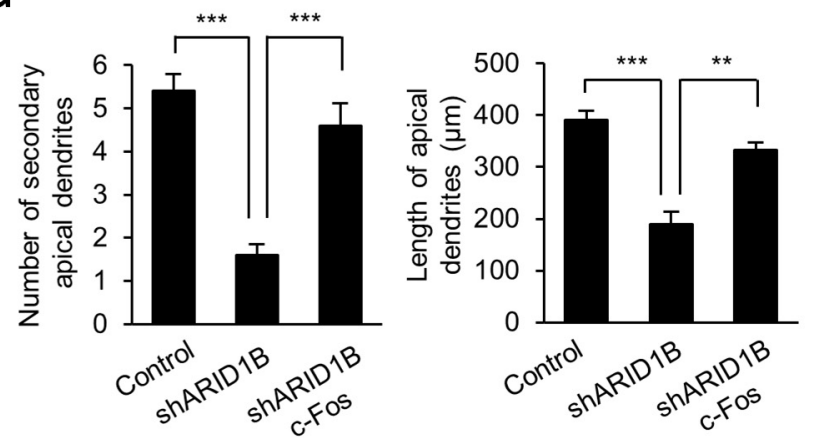

Figure 9. Interaction of ARID1B with c-Fos and Arc genes in dendritic growth. A, ARID1B interacts with c-Fos and Arc promoters. ChIP assays were performed using brain lysates from E18.5 mice. After cross-linking and sonication, lysates were immunoprecipitated with an antibody to acetyl-histone H3 (positive control) or ARID1B. IgG fraction was used as a negative control. Then, c-Fos or Arc promoters were amplified by PCR. B, ARID1B knockdown reduces Brg1 binding to c-Fos and Arc promoters. Cortical neurons from E16.5 mice were cultured and infected with a lentivirus, pLVX-shARID1B. Cellular lysates from the cultures were subjected to ChIP-PCR. C, Quantification of $\boldsymbol{B}$. The band intensities were measured using ImageJ. $n=3$ (Figure legend continues.) 
of the SWI/SNF complex, are required for activity-dependent dendritic outgrowth and synaptic plasticity in the brain $(\mathrm{Wu}$ et al., 2007; Yoo et al., 2009; Vogel-Ciernia et al., 2013). Thus, our data are consistent with these previous findings and suggest a critical role for the complex in neural circuitry formation in the developing brain.

Our data showed that dendritic outgrowth and branching into layer I were markedly decreased in ARID1B-deficient neurons. Layer I is a largely cell-free zone, originating from the marginal zone of the developing cortical plate (Marín-Padilla, 1990). This layer contains mainly apical dendritic extensions of layer II/III pyramidal neurons and horizontally oriented axons from subcortical regions (Wyss et al., 1990; Shipp, 2007). Studies have shown that dendrites in cortical layer I receive long-range inputs from multiple brain regions, including the cortex itself and thalamic areas (Cauller, 1995; Rubio-Garrido et al., 2009), as well as local inputs of GABAergic interneurons (Schwartz et al., 1998; Soda et al., 2003). Thus, inputs into the apical dendrites in layer I are crucial for the feedback interactions in the cerebral cortex that are involved in associative learning and attention. These findings suggest that the ARID1B-associated pathology is attributed to the defective reception of inputs within layer I. Interestingly, disrupted balance between inhibitory and excitatory transmission is implicated in neurodevelopmental disorders (Rubenstein and Merzenich, 2003; Ramamoorthi and Lin, 2011). For example, inhibitory input is more severely decreased than excitatory drive in the UBE3A mutant mouse, a model of Angelman syndrome featuring intellectual disability and seizure susceptibility (Wallace et al., 2012). Thus, the decreased dendritic innervation into layer I caused by ARID1B deficiency may disrupt to receive balanced excitatory and inhibitory inputs and thereby to create pathologic conditions of intellectual disability.

Spines form abnormally in ARID1B-deficient neurons, featuring a decrease in spine numbers and the prevalence of filopodia-like immature spines. Abnormalities in dendritic spine formation and dynamics are found in neurodevelopmental disorders associated with intellectual disabilities (Purpura, 1974; Fiala et al., 2002). Furthermore, a reduction in spine size along dendrites has been reported in people with Down syndrome and schizophrenia (MarínPadilla, 1976; Roberts et al., 1996). The morphological abnormality is functionally relevant, given that ARID1B deficiency suppresses excitatory and inhibitory synaptic transmission. Thus, our results suggest that the synaptic maturation process is dependent on ARID1B activity and that ARID1B insufficiency contributes to clinical outcomes by creating inappropriate synaptic connectivity and transmission. Structural changes of dendritic spines

\section{$\leftarrow$}

(Figure legend continued.) independent cortical cultures using three mice. Statistical significance was determined by two-tailed Student's $t$ test. ${ }^{*} p<0.5,{ }^{* *} p<0.01,{ }^{* * *} p<0.001 . \boldsymbol{D}$, Cortical neurons from E18.5 mice were cultured for $3 \mathrm{~d}$ after transfecting them with a control shRNA, shARID1B, a c-Fos plasmid, an Arc plasmid, shARID1B, and a c-Fos plasmid, or shARID1B and an ARC plasmid. Dendritic morphology was examined by immunostaining with a MAP2 antibody. Transfection of either a c-Fos plasmid or an Arc plasmid partially suppressed the shARID1B effect on dendritic growth. Scale bars, $10 \mu \mathrm{m}$. E, Quantification of dendritic numbers and lengths in neurons transfected with plasmids described in $\boldsymbol{D} . n=75$ cells from three independent cultures using three mice for each condition. Statistical significance was determined by one-way ANOVA with Bonferroni correction test. ${ }^{* *} p<0.01$, ${ }^{* * *} p<0.001 . F$, Either shARID1B or shARID1B and a c-Fos construct was electroporated into E14.5 embryos in utero, and cortical dendrites were assessed at P14. Coexpression of c-Fos partially suppressed the inhibitory effect of shARID1B. G, Quantification of the number and length of dendrites. $n=40$ cells from five mice for each condition. Statistical significance was determined by two-tailed Student's $t$ test. ${ }^{* *} p<0.01,{ }^{* * *} p<0.001$. are correlated with functional changes of neural circuitry during experience-dependent plasticity (Matsuzaki et al., 2004; Holtmaat et al., 2006; Tropea et al., 2010). It will be interesting to test whether the spines absent ARID1B can undergo structural and functional plasticity.

Although ARID1B is a chromatin remodeler, little is known about the genes downstream of ARID1B in neural cells. We found that ARID1B deficiency suppressed c-Fos and Arc expression. c-Fos and Arc and their upstream inducers, such as CREB and JNK, play critical roles in dendritic and synaptic development (Redmond et al., 2002; Kwon et al., 2011; de Anda et al., 2012). For example, mice lacking c-Fos show aberrant synaptic plasticity (Fleischmann et al., 2003). Arc mRNA is selectively localized to dendrites and spines (Lyford et al., 1995; Steward et al., 1998). CREB phosphorylation induces dendritic arborization by activating downstream target genes (Redmond et al., 2002; Kwon et al., 2011). Activation of JNK modulates dendritic formation in the developing cortex (de Anda et al., 2012). Thus, our data showing ARID1B deficiency leads to aberrant expression of c-Fos and Arc, and their upstream inducers suggest that ARID1B regulates dendritic/spine differentiation via JNK/ CREB-mediated c-Fos and/or Arc expression. Interestingly, these factors are downstream targets of neurotrophin signaling (Ying et al., 2002; Calella et al., 2007). ARID1B may play a role in dendrite and synaptic development by participating in neurotrophin-mediated c-Fos and/or Arc expression. Our data suggest that ARID1B directly controls c-Fos and Arc gene expression by binding to these promoters. Given that ARID1B knockdown modulates the interaction affinity of Brgl in c-Fos and Arc promoters, ARID1B may facilitate the access of other components of the SWI/SNF complex (or other chromatin modifiers) for c-Fos and Arc expression. ARID1B knockdown alters the expression of genes that promote neuronal migration and neurite outgrowth, such as GAP43, GPRN1, and STMN2. The reduction in GPRIN1 draws attention because G-protein signaling has been exploited for therapeutic targeting. Additionally, we noticed that ARID1B deficiency induced a decrease in STMN2 level in cortical neurons. Reduced expression of this gene is associated with Rett syndrome (Nectoux et al., 2010), suggesting that the regulation of STMN2 level is a core mechanism of ARID1B neural functions.

Coffin-Siris syndrome features developmental disability in anatomy and behavior. Intellectual disability is a major characteristic for individuals with this condition (Fleck et al., 2001; Schrier et al., 2012). Our findings are relevant to the developmental delay noted in children with Coffin-Siris syndrome. Furthermore, haploinsufficiency of ARID1B causes intellectual disability (Hoyer et al., 2012). Our mouse model, using in utero electroporation with shRNA, knocks down the ARID1B gene but does not completely remove the gene product. Thus, this animal model can nicely represent the pathological conditions of intellectual disability, including Coffin-Siris syndrome. Treatment for intellectual disability may eventually be developed by modulating activities of chromatin remodeling components. For example, a recent study (Li et al., 2010) showed that ARID1B has E3 ubiquitin ligase activity and targets histone H2B. E3 ubiquitin ligases and histone $\mathrm{H} 2 \mathrm{~B}$ play critical roles in neuronal morphogenesis (Vadhvani et al., 2013; Wong et al., 2013; Ishino et al., 2014). In this regard, further studies on the biochemical roles of ARID1B need to be elucidated.

\section{References}

Alvarez VA, Ridenour DA, Sabatini BL (2006) Retraction of synapses and dendritic spines induced by off-target effects of RNA interference. J Neurosci 26:7820-7825. CrossRef Medline

Armstrong DD (2005) Neuropathology of Rett syndrome. J Child Neurol 20:747-753. CrossRef Medline

Baek ST, Kerjan G, Bielas SL, Lee JE, Fenstermaker AG, Novarino G, Gleeson 
JG (2014) Off-target effect of doublecortin family shRNA on neuronal migration associated with endogenous microRNA dysregulation. Neuron 82:1255-1262. CrossRef Medline

Bauer M, Kinkl N, Meixner A, Kremmer E, Riemenschneider M, Förstl H, Gasser T, Ueffing M (2009) Prevention of interferon-stimulated gene expression using microRNA-designed hairpins. Gene Ther 16:142-147. CrossRef Medline

Belichenko PV, Oldfors A, Hagberg B, Dahlström A (1994) Rett syndrome: 3-D confocal microscopy of cortical pyramidal dendrites and afferents. Neuroreport 5:1509-1513. CrossRef Medline

Calella AM, Nerlov C, Lopez RG, Sciarretta C, von Bohlen und Halbach O, Bereshchenko O, Minichiello L (2007) Neurotrophin/Trk receptor signaling mediates C/EBPalpha, -beta and NeuroD recruitment to immediate-early gene promoters in neuronal cells and requires C/EBPs to induce immediate-early gene transcription. Neural Dev 2:4. CrossRef Medline

Calfa G, Percy AK, Pozzo-Miller L (2011) Experimental models of Rett syndrome based on Mecp2 dysfunction. Exp Biol Med (Maywood) 236:3-19. CrossRef Medline

Cauller L (1995) Layer I of primary sensory neocortex: where top-down converges upon bottom-up. Behav Brain Res 71:163-170. CrossRef Medline

Costes SV, Daelemans D, Cho EH, Dobbin Z, Pavlakis G, Lockett S (2004) Automatic and quantitative measurement of protein-protein colocalization in live cells. Biophys J 86:3993-4003. CrossRef Medline

Daily DK, Ardinger HH, Holmes GE (2000) Identification and evaluation of mental retardation. Am Fam Physician 61:1059-1067, 1070. Medline

de Anda FC, Rosario AL, Durak O, Tran T, Gräff J, Meletis K, Rei D, Soda T, Madabhushi R, Ginty DD, Kolodkin AL, Tsai LH (2012) Autism spectrum disorder susceptibility gene TAOK2 affects basal dendrite formation in the neocortex. Nat Neurosci 15:1022-1031. CrossRef Medline

De Rubeis S, He X, Goldberg AP, Poultney CS, Samocha K, Cicek AE, Kou Y, Liu L, Fromer M, Walker S, Singh T, Klei L, Kosmicki J, Shih-Chen F, Aleksic B, Biscaldi M, Bolton PF, Brownfeld JM, Cai J, Campbell NG, et al. (2014) Synaptic, transcriptional and chromatin genes disrupted in autism. Nature 515:209-215. CrossRef Medline

Dull T, Zufferey R, Kelly M, Mandel RJ, Nguyen M, Trono D, Naldini L (1998) A third-generation lentivirus vector with a conditional packaging system. J Virol 72:8463-8471. Medline

Ellison JW, Rosenfeld JA, Shaffer LG (2013) Genetic basis of intellectual disability. Annu Rev Med 64:441-450. CrossRef Medline

Fiala JC, Spacek J, Harris KM (2002) Dendritic spine pathology: cause or consequence of neurological disorders? Brain Res Brain Res Rev 39: 29-54. CrossRef Medline

Fleck BJ, Pandya A, Vanner L, Kerkering K, Bodurtha J (2001) Coffin-Siris syndrome: review and presentation of new cases from a questionnaire study. Am J Med Genet 99:1-7. CrossRef Medline

Fleischmann A, Hvalby O, Jensen V, Strekalova T, Zacher C, Layer LE, Kvello A, Reschke M, Spanagel R, Sprengel R, Wagner EF, Gass P (2003) Impaired long-term memory and NR2A-type NMDA receptor-dependent synaptic plasticity in mice lacking c-Fos in the CNS. J Neurosci 23: 9116-9122. Medline

Fukuda T, Itoh M, Ichikawa T, Washiyama K, Goto Y (2005) Delayed maturation of neuronal architecture and synaptogenesis in cerebral cortex of Mecp2-deficient mice. J Neuropathol Exp Neurol 64:537-544. CrossRef Medline

Halgren C, Kjaergaard S, Bak M, Hansen C, El-Schich Z, Anderson CM, Henriksen KF, Hjalgrim H, Kirchhoff M, Bijlsma EK, Nielsen M, den Hollander NS, Ruivenkamp CA, Isidor B, Le Caignec C, Zannolli R, Mucciolo M, Renieri A, Mari F, Anderlid BM, et al. (2012) Corpus callosum abnormalities, intellectual disability, speech impairment, and autism in patients with haploinsufficiency of ARID1B. Clin Genet 82:248-255. CrossRef Medline

Ho L, Crabtree GR (2010) Chromatin remodelling during development. Nature 463:474-484. CrossRef Medline

Holtmaat A, Wilbrecht L, Knott GW, Welker E, Svoboda K (2006) Experience-dependent and cell-type-specific spine growth in the neocortex. Nature 441:979-983. CrossRef Medline

Hoyer J, Ekici AB, Endele S, Popp B, Zweier C, Wiesener A, Wohlleber E, Dufke A, Rossier E, Petsch C, Zweier M, Göhring I, Zink AM, Rappold G, Schröck E, Wieczorek D, Riess O, Engels H, Rauch A, Reis A (2012) Haploinsufficiency of ARID1B, a member of the SWI/SNF-a chromatin- remodeling complex, is a frequent cause of intellectual disability. Am J Hum Genet 90:565-572. CrossRef Medline

Huttenlocher PR (1974) Dendritic development in neocortex of children with mental defect and infantile spasms. Neurology 24:203-210. CrossRef Medline

Iossifov I, O’Roak BJ, Sanders SJ, Ronemus M, Krumm N, Levy D, Stessman HA, Witherspoon KT, Vives L, Patterson KE, Smith JD, Paeper B, Nickerson DA, Dea J, Dong S, Gonzalez LE, Mandell JD, Mane SM, Murtha MT, Sullivan CA, et al. (2014) The contribution of de novo coding mutations to autism spectrum disorder. Nature 515:216-221. CrossRef Medline

Ishino Y, Hayashi Y, Naruse M, Tomita K, Sanbo M, Fuchigami T, Fujiki R, Hirose K, Toyooka Y, Fujimori T, Ikenaka K, Hitoshi S (2014) Brela, a histone h2b ubiquitin ligase, regulates the cell cycle and differentiation of neural precursor cells. J Neurosci 34:3067-3078. CrossRef Medline

Jentarra GM, Olfers SL, Rice SG, Srivastava N, Homanics GE, Blue M, Naidu S, Narayanan V (2010) Abnormalities of cell packing density and dendritic complexity in the MeCP2 A140V mouse model of Rett syndrome/ X-linked mental retardation. BMC Neurosci 11:19. CrossRef Medline

Jiang M, Ash RT, Baker SA, Suter B, Ferguson A, Park J, Rudy J, Torsky SP, Chao HT, Zoghbi HY, Smirnakis SM (2013) Dendritic arborization and spine dynamics are abnormal in the mouse model of MECP2 duplication syndrome. J Neurosci 33:19518-19533. CrossRef Medline

Ka M, Condorelli G, Woodgett JR, Kim WY (2014a) mTOR regulates brain morphogenesis by mediating GSK3 signaling. Development 141: 4076-4086. CrossRef Medline

Ka M, Jung EM, Mueller U, Kim WY (2014b) MACF1 regulates the migration of pyramidal neurons via microtubule dynamics and GSK-3 signaling. Dev Biol 395:4-18. CrossRef Medline

Kaufmann WE, Moser HW (2000) Dendritic anomalies in disorders associated with mental retardation. Cereb Cortex 10:981-991. CrossRef Medline

Kim WY, Horbinski C, Sigurdson W, Higgins D (2004) Proteasome inhibitors suppress formation of polyglutamine-induced nuclear inclusions in cultured postmitotic neurons. J Neurochem 91:1044-1056. CrossRef Medline

Kim WY, Fayazi Z, Bao X, Higgins D, Kazemi-Esfarjani P (2005) Evidence for sequestration of polyglutamine inclusions by Drosophila myeloid leukemia factor. Mol Cell Neurosci 29:536-544. CrossRef Medline

Kim WY, Zhou FQ, Zhou J, Yokota Y, Wang YM, Yoshimura T, Kaibuchi K, Woodgett JR, Anton ES, Snider WD (2006) Essential roles for GSK-3s and GSK-3-primed substrates in neurotrophin-induced and hippocampal axon growth. Neuron 52:981-996. CrossRef Medline

Kim WY, Wang X, Wu Y, Doble BW, Patel S, Woodgett JR, Snider WD (2009a) GSK-3 is a master regulator of neural progenitor homeostasis. Nat Neurosci 12:1390-1397. CrossRef Medline

Kim WY, Gonsiorek EA, Barnhart C, Davare MA, Engebose AJ, Lauridsen H, Bruun D, Lesiak A, Wayman G, Bucelli R, Higgins D, Lein PJ (2009b) Statins decrease dendritic arborization in rat sympathetic neurons by blocking RhoA activation. J Neurochem 108:1057-1071. CrossRef Medline

Kwon M, Fernández JR, Zegarek GF, Lo SB, Firestein BL (2011) BDNFpromoted increases in proximal dendrites occur via CREB-dependent transcriptional regulation of cypin. J Neurosci 31:9735-9745. CrossRef Medline

Li XS, Trojer P, Matsumura T, Treisman JE, Tanese N (2010) Mammalian SWI/SNF - a subunit BAF250/ARID1 is an E3 ubiquitin ligase that targets histone H2B. Mol Cell Biol 30:1673-1688. CrossRef Medline

Lyford GL, Yamagata K, Kaufmann WE, Barnes CA, Sanders LK, Copeland NG, Gilbert DJ, Jenkins NA, Lanahan AA, Worley PF (1995) Arc, a growth factor and activity-regulated gene, encodes a novel cytoskeletonassociated protein that is enriched in neuronal dendrites. Neuron 14: 433-445. CrossRef Medline

Machado-Salas JP (1984) Abnormal dendritic patterns and aberrant spine development in Bourneville's disease-a Golgi survey. Clin Neuropathol 3:52-58. Medline

Marín-Padilla M (1976) Pyramidal cell abnormalities in the motor cortex of a child with Down's syndrome. A Golgi study. J Comp Neurol 167:63-81. CrossRef Medline

Marín-Padilla M (1990) Three-dimensional structural organization of layer I of the human cerebral cortex: a Golgi study. J Comp Neurol 299:89-105. CrossRef Medline

Matsuzaki M, Honkura N, Ellis-Davies GC, Kasai H (2004) Structural basis 
of long-term potentiation in single dendritic spines. Nature 429:761-766. CrossRef Medline

Maulik PK, Mascarenhas MN, Mathers CD, Dua T, Saxena S (2011) Prevalence of intellectual disability: a meta-analysis of population-based studies. Res Dev Disabil 32:419-436. CrossRef Medline

Nectoux J, Fichou Y, Rosas-Vargas H, Cagnard N, Bahi-Buisson N, Nusbaum P, Letourneur F, Chelly J, Bienvenu T (2010) Cell cloning-based transcriptome analysis in Rett patients: relevance to the pathogenesis of Rett syndrome of new human MeCP2 target genes. J Cell Mol Med 14: 1962-1974. CrossRef Medline

Nectoux J, Florian C, Delepine C, Bahi-Buisson N, Khelfaoui M, Reibel S, Chelly J, Bienvenu T (2012) Altered microtubule dynamics in Mecp2deficient astrocytes. J Neurosci Res 90:990-998. CrossRef Medline

Nordman JC, Kabbani N (2012) An interaction between alpha7 nicotinic receptors and a G-protein pathway complex regulates neurite growth in neural cells. J Cell Sci 125:5502-5513. CrossRef Medline

Purpura DP (1974) Dendritic spine "dysgenesis" and mental retardation. Science 186:1126-1128. CrossRef Medline

Ramamoorthi K, Lin Y (2011) The contribution of GABAergic dysfunction to neurodevelopmental disorders. Trends Mol Med 17:452-462. CrossRef Medline

Ravelli RB, Gigant B, Curmi PA, Jourdain I, Lachkar S, Sobel A, Knossow M (2004) Insight into tubulin regulation from a complex with colchicine and a stathmin-like domain. Nature 428:198-202. CrossRef Medline

Redmond L, Kashani AH, Ghosh A (2002) Calcium regulation of dendritic growth via CaM kinase IV and CREB-mediated transcription. Neuron 34:999-1010. CrossRef Medline

Roberts RC, Conley R, Kung L, Peretti FJ, Chute DJ (1996) Reduced striatal spine size in schizophrenia: a postmortem ultrastructural study. Neuroreport 7:1214-1218. CrossRef Medline

Ronan JL, Wu W, Crabtree GR (2013) From neural development to cognition: unexpected roles for chromatin. Nat Rev Genet 14:347-359. CrossRef Medline

Ropers HH (2010) Genetics of early onset cognitive impairment. Annu Rev Genomics Hum Genet 11:161-187. CrossRef Medline

Rubenstein JL, Merzenich MM (2003) Model of autism: increased ratio of excitation/inhibition in key neural systems. Genes Brain Behav 2:255-267. CrossRef Medline

Rubio-Garrido P, Pérez-de-Manzo F, Porrero C, Galazo MJ, Clascá F (2009) Thalamic input to distal apical dendrites in neocortical layer 1 is massive and highly convergent. Cereb Cortex 19:2380-2395. CrossRef Medline

Saito TH, Uda S, Tsuchiya T, Ozaki Y, Kuroda S (2013) Temporal decoding of MAP kinase and CREB phosphorylation by selective immediate early gene expression. PLoS One 8:e57037. CrossRef Medline

Samaco RC, Neul JL (2011) Complexities of Rett syndrome and MeCP2. J Neurosci 31:7951-7959. CrossRef Medline

Santen GW, Aten E, Sun Y, Almomani R, Gilissen C, Nielsen M, Kant SG, Snoeck IN, Peeters EA, Hilhorst-Hofstee Y, Wessels MW, den Hollander NS, Ruivenkamp CA, van Ommen GJ, Breuning MH, den Dunnen JT, van Haeringen A, Kriek M (2012) Mutations in SWI/SNF chromatin remodeling complex gene ARID1B cause Coffin-Siris syndrome. Nat Genet 44:379-380. CrossRef Medline

Sausen M, Leary RJ, Jones S, Wu J, Reynolds CP, Liu X, Blackford A, Parmigiani G, Diaz LA Jr, Papadopoulos N, Vogelstein B, Kinzler KW, Velculescu VE, Hogarty MD (2013) Integrated genomic analyses identify ARID1A and ARID1B alterations in the childhood cancer neuroblastoma. Nat Genet 45:12-17. CrossRef Medline

Schrier SA, Bodurtha JN, Burton B, Chudley AE, Chiong MA, D'avanzo MG, Lynch SA, Musio A, Nyazov DM, Sanchez-Lara PA, Shalev SA, Deardorff MA (2012) The Coffin-Siris syndrome: a proposed diagnostic approach and assessment of 15 overlapping cases. Am J Med Genet A 158A:18651876. CrossRef Medline

Schwartz TH, Rabinowitz D, Unni V, Kumar VS, Smetters DK, Tsiola A,
Yuste R (1998) Networks of coactive neurons in developing layer 1. Neuron 20:541-552. CrossRef Medline

Shipp S (2007) Structure and function of the cerebral cortex. Curr Biol 17: R443-R449. CrossRef Medline

Skene JH (1989) Axonal growth-associated proteins. Annu Rev Neurosci 12:127-156. CrossRef Medline

Soda T, Nakashima R, Watanabe D, Nakajima K, Pastan I, Nakanishi S (2003) Segregation and coactivation of developing neocortical layer 1 neurons. J Neurosci 23:6272-6279. Medline

Steward O, Wallace CS, Lyford GL, Worley PF (1998) Synaptic activation causes the mRNA for the IEG Arc to localize selectively near activated postsynaptic sites on dendrites. Neuron 21:741-751. CrossRef Medline

Tropea D, Majewska AK, Garcia R, Sur M (2010) Structural dynamics of synapses in vivo correlate with functional changes during experiencedependent plasticity in visual cortex. J Neurosci 30:11086-11095. CrossRef Medline

Trotter KW, Archer TK (2008) The BRG1 transcriptional coregulator. Nucl Recept Signal 6:e004. CrossRef Medline

Tsurusaki Y, Okamoto N, Ohashi H, Kosho T, Imai Y, Hibi-Ko Y, Kaname T, Naritomi K, Kawame H, Wakui K, Fukushima Y, Homma T, Kato M, Hiraki Y, Yamagata T, Yano S, Mizuno S, Sakazume S, Ishii T, Nagai T, et al. (2012) Mutations affecting components of the SWI/SNF complex cause Coffin-Siris syndrome. Nat Genet 44:376-378. CrossRef Medline

Vadhvani M, Schwedhelm-Domeyer N, Mukherjee C, Stegmüller J (2013) The centrosomal E3 ubiquitin ligase FBXO31-SCF regulates neuronal morphogenesis and migration. PLoS One 8:e57530. CrossRef Medline

Vogel-Ciernia A, Matheos DP, Barrett RM, Kramár EA, Azzawi S, Chen Y, Magnan CN, Zeller M, Sylvain A, Haettig J, Jia Y, Tran A, Dang R, Post RJ, Chabrier M, Babayan AH, Wu JI, Crabtree GR, Baldi P, Baram TZ, et al. (2013) The neuron-specific chromatin regulatory subunit BAF53b is necessary for synaptic plasticity and memory. Nat Neurosci 16:552-561. CrossRef Medline

Wallace ML, Burette AC, Weinberg RJ, Philpot BD (2012) Maternal loss of Ube3a produces an excitatory/inhibitory imbalance through neuron type-specific synaptic defects. Neuron 74:793-800. CrossRef Medline

Wang W, Xue Y, Zhou S, Kuo A, Cairns BR, Crabtree GR (1996) Diversity and specialization of mammalian SWI/SNF complexes. Genes Dev 10: 2117-2130. CrossRef Medline

Wang X, Nagl NG, Wilsker D, Van Scoy M, Pacchione S, Yaciuk P, Dallas PB, Moran E (2004) Two related ARID family proteins are alternative subunits of human SWI/SNF complexes. Biochem J 383:319-325. CrossRef Medline

Wong JJ, Li S, Lim EK, Wang Y, Wang C, Zhang H, Kirilly D, Wu C, Liou YC, Wang H, Yu F (2013) A Cullin1-based SCF E3 ubiquitin ligase targets the InR/PI3K/TOR pathway to regulate neuronal pruning. PLoS Biol 11: e1001657. CrossRef Medline

Wu JI, Lessard J, Olave IA, Qiu Z, Ghosh A, Graef IA, Crabtree GR (2007) Regulation of dendritic development by neuron-specific chromatin remodeling complexes. Neuron 56:94-108. CrossRef Medline

Wyss JM, Van Groen T, Sripanidkulchai K (1990) Dendritic bundling in layer I of granular retrosplenial cortex: intracellular labeling and selectivity of innervation. J Comp Neurol 295:33-42. CrossRef Medline

Yan Z, Wang Z, Sharova L, Sharov AA, Ling C, Piao Y, Aiba K, Matoba R, Wang W, Ko MS (2008) BAF250B-associated SWI/SNF chromatinremodeling complex is required to maintain undifferentiated mouse embryonic stem cells. Stem Cells 26:1155-1165. CrossRef Medline

Ying SW, Futter M, Rosenblum K, Webber MJ, Hunt SP, Bliss TV, Bramham CR (2002) Brain-derived neurotrophic factor induces long-term potentiation in intact adult hippocampus: requirement for ERK activation coupled to CREB and upregulation of Arc synthesis. J Neurosci 22:1532-1540. Medline

Yoo AS, Staahl BT, Chen L, Crabtree GR (2009) MicroRNA-mediated switching of chromatin-remodelling complexes in neural development. Nature 460:642-646. CrossRef Medline 